\title{
The Cross-Sectional Dispersion of Commercial Real Estate Returns and Rent Growth: Time Variation and Economic Fluctuations
}

\author{
Alberto Plazzi ${ }^{*} \quad$ Walter Torous ${ }^{\dagger} \quad$ Rossen Valkanov ${ }^{\ddagger}$
}

We estimate the cross-sectional dispersions of returns and growth in rents for commercial real estate using data on U.S. metropolitan areas over the sample period 1986 to 2002. The cross-sectional dispersion of returns is a measure of the risk faced by commercial real estate investors. We document that for apartments, offices, industrial and retail properties, the cross-sectional dispersions are timevarying. Interestingly, their time series fluctuations can be explained by macroeconomic variables such as the term and credit spreads, inflation, and the short rate of interest. The cross-sectional dispersions also exhibit an asymmetrically larger response to negative economics shocks, which may be attributable to credit channel effects impacting the availability of external debt financing to commercial real estate investments. Finally, we find a statistically reliable positive relation between commercial real estate returns and their cross-sectional dispersion, suggesting that idiosyncratic fluctuations are priced in the commercial real estate market.

\section{Introduction}

Time variation in equity risk and its relation to the state of the economy has been widely documented at both the firm and market levels (see, for example, Bollerslev, Chou, and Kroner (1992), Ghysels, Harvey, and Renault (1996), Campbell, Lettau, Malkiel, and Xu (2001) and Goyal and Santa-Clara (2003) among others). Comparatively little, however, is known about risk dynamics in the commercial real estate market and their link to prevailing economic conditions.

\footnotetext{
*UCLA Anderson School and SAFE Center University of Verona, 110 Westwood Plaza, Los Angeles, CA 900951481, e-mail: alberto.plazzi.2010@anderson.ucla.edu.

${ }^{\dagger}$ UCLA Anderson School, 110 Westwood Plaza, Los Angeles, CA 90095-1481, e-mail: walter.n.torous@anderson.ucla.edu.

${ }^{\ddagger}$ The Rady School at UCSD, Pepper Canyon Hall, 9500 Gilman Drive, MC 0093, La Jolla, CA 92093, e-mail: rvalkanov@ucsd.edu.
} 
This scarcity of empirical facts is not due to a lack of investor interest. To the contrary, the commercial real estate market is large and represents a significant fraction of total U.S. wealth. For example, at year end 2004, estimates put the value of the U.S. commercial real estate market at $\$ 8$ trillion as compared to the U.S. stock market's value of almost $\$ 18$ trillion.

We investigate risk dynamics in the commercial real estate market by evaluating the cross-sectional dispersions of commercial real estate returns and rental growth rates across U.S. metropolitan areas. The cross-sectional dispersion of commercial real estate returns is a more appropriate measure of the risk inherent in commercial real estate because it captures idiosyncratic fluctuations associated with this asset that are unlikely to be diversified away. Unlike equities, the commercial real estate market is characterized by the buying and selling of individual assets, the value of each property representing a non-trivial share of most investors' portfolios. This being the case, the volatility of aggregate real estate indices will not accurately reflect the risk exposure of a typical investor holding commercial real estate. Also, as commercial real estate tends to be affected by geographic, demographic, urban, and other local economic factors, the dispersion of commercial real estate returns will capture idiosyncratic fluctuations arising from local shocks as well as fluctuations due to common aggregate factors. Similarly, the dispersion of the growth in rents reflects market-wide and region-specific fluctuations.

As a first step in our investigation, we document the times series behavior of the cross-sectional dispersions of commercial real estate returns and rental growth rates. We use data from Global Real Analytics (GRA) covering apartments, office buildings, and retail and industrial properties. The data are available at a bi-annual frequency over the 1986 to 2002 sample period for a number of U.S. metropolitan areas. While the GRA data are not without limitations, they have the advantage of providing information across a large cross-section of metropolitan areas.

We find that the dispersions of returns and rental growth rates for all property types vary significantly over our sample period. For example, the return dispersions of apartments, industrial and office properties range from between $2.3 \%$ and $14.6 \%$ per year. These dispersions are found to be time varying and serially correlated. However, this serial dependence is not integrated, suggesting that the fluctuations are not driven solely by trends in demographic or geographic factors, which, 
by contrast, are more persistent in nature. In fact, the time series properties of the cross-sectional dispersions are similar to those of economic variables such as the term and credit spreads, inflation, and the three-month Treasury bill rate, all of which are relied upon in the finance literature to proxy for the prevailing state of the economy.

Based on this observation, we conjecture that the cross-sectional dispersions are driven by fluctuations in these macroeconomic variables. The intuition for this argument is based on the fact that the propagation and persistence of business cycle fluctuations vary across regions because of corresponding differences in industry composition, in firm sizes, and differences in the availability of funds across states (Carlino and DeFina (2003), Owyang, Piger, and Wall (2003), Fratantoni and Schuh (2003), Owyang and Wall (2004)). As a case in point, the 2001 recession was felt heavily in the San Francisco office market, which posted an annual return of $-11.8 \%$, while during that same year office prices in Oklahoma City increased by 11.5\%. To the extent that economic shocks are propagated differentially across regions, we should expect cross-sectional dispersions to also change with prevailing economic conditions.

Consistent with this conjecture, we find that the cross-sectional dispersions of commercial real estate returns and rental growth rates are higher (lower) in periods when the term spread is wider (narrower). Since the term spread is closely related to shorter-term business cycles as identified by the National Bureau of Economic Research (NBER) (Fama and French (1989)), with the term spread being wider in a business cycle downturn and narrower in a business cycle expansion, our evidence suggests that the cross-sectional dispersions behave counter-cyclically. These results apply across property types, though this business cycle effect on the dispersion of returns and rental growth rates appears to be larger for apartment, industrial and office properties than for retail properties.

We also find that a narrower (wider) credit spread is correlated with subsequently higher (lower) cross-sectional dispersions of commercial real estate returns and rental growth rates. This result points to the importance of external debt financing and the underlying credit channel of monetary policy transmission to the commercial real estate market. As argued by, for example, Bernanke and Gertler (1995), economic shocks amplify frictions already prevailing in credit markets because 
of asymmetric information and the costly enforcement of contracts which, in turn, significantly affects the premium on external debt financing. Our evidence suggests that the widening of the credit spread, consistent with tightening conditions in credit markets and more expensive external debt financing, results not only in lower commercial real estate valuations but also increases the cross-sectional dispersions of returns and rental growth rates.

Cross-sectional differences in the characteristics of commercial properties can also give rise to the observed fluctuations in the dispersions of returns and rental growth rates even if economic shocks are propagated uniformly across regions. For example, the fluctuations in cross-sectional dispersions would arise if the reliance on debt to finance commercial real estate varies across regions. If this is the case and since negative economic shocks tend to be sharper than positive shocks, we should observe an asymmetric behavior in dispersions, with negative shocks resulting in larger increases than positive shocks. Our empirical evidence is consistent with this asymmetric behavior in the cross-sectional dispersions for apartments as well as office buildings.

We also test whether commercial real estate investors are compensated for their idiosyncratic risk exposure. This question is directly related to the ongoing debate in the finance literature of whether idiosyncratic risk is priced in the equities market. Early examples of this research are Lintner (1965) and Douglas (1969), while recent papers by Campbell, Lettau, Malkiel, and Xu (2001) and Goyal and Santa-Clara (2003) have rekindled this discussion. To the extent that fluctuations in real estate valuations are more difficult to diversify, commercial real estate investors would require compensation for such risk. However, because commercial real estate's risk characteristics vary with the state of the economy, it is important that any test of the total risk-return tradeoff in commercial real estate also includes variables proxying for the time variation in economic conditions. Doing so, we find that the total risk-return tradeoff is positive and statistically significant for three of the four commercial property types - apartments, offices and retail properties.

The plan of the paper is as follows. In Section 2 we describe the data used in this study. Section 3 presents the measures of cross-sectional dispersion and analyzes their statistical properties. In Section 4 we link the fluctuations in the cross-sectional dispersion measures to economic variables that are known to proxy for the state of the economy. We also investigate the possibility of 
asymmetry in the time series behavior of these cross-sectional dispersions consistent with the reliance on debt to finance commercial real estate varying across regions. Section 5 investigates the total risk-return relation for commercial real estate. We provide reliable evidence that idiosyncratic fluctuations in apartments, offices and retail properties are priced. Section 6 concludes.

\section{The Data}

\section{Commercial Real Estate Data}

Our commercial real estate data includes both prices and annual cap rates (net rents expressed as a fraction of price) of class A apartments, industrial, retail, and office properties for a number of U.S. metropolitan areas (MSAs). The data are provided by Global Real Analytics (GRA) and cover the sample period beginning in December 1985 and ending in March 2003. These data are available bi-annually from 1985 to 1993 and quarterly from 1994 onwards. Twenty-one MSAs are included in 1985, increasing to twenty-three in 1988. The number of MSAs in the data increases to forty-eight in 1989 and fifty-eight MSAs are covered by GRA at the end of our sample period. In order to avail ourselves of as much data as is available, we sample prices and cap rates biannually from all available MSAs, beginning in December 1985 (1985:12) and ending in December 2002 (2002:12). Given annual cap rates, $C A P_{t}$, and corresponding prices, $P_{t}$, of a particular property type in a given area, we construct biannual net rents in that period as $H_{t}=\frac{C A P_{t} \times P_{t}}{2}$. The gross returns $1+R_{t}$ in period $t$ are then calculated as $\frac{P_{t}+H_{t}}{P_{t-1}}$ while one plus the growth in rents is given by $\frac{H_{t}}{H_{t-1}}$. Our analysis will focus on the cross-sectional dispersion of log excess returns, calculated as $\ln \left(1+R_{t}\right)-\ln \left(1+R_{t}^{T b l}\right)$, where $R_{t}^{T b l}$ is the three-month Treasury bill yield, ${ }^{1}$ and on the crosssectional dispersion of $\log$ rent growth rates, $G H_{t}=\ln \left(\frac{H_{t}}{H_{t-1}}\right)$.

An attractive feature of the GRA data is that it is available for a cross-section of metropolitan areas. This cross-sectional feature is crucial to our study as we are interested in the dispersion of returns and rental growth rates across metropolitan areas. In addition, GRA provides averages of transactions data rather than appraisal values.

While there are well known difficulties associated with appraisal data, the GRA data are not

\footnotetext{
${ }^{1}$ When there is no possibility of confusion, we will refer to excess returns simply as returns. Consistent with this, henceforth we will use the notation $R$ to refer to excess returns.
} 
without their own limitations. For example, commercial properties are much more heterogeneous than single-family homes and transact infrequently. Liquidity in the commercial property market can vary substantially over time and space. Because we cannot control for the specific characteristics of properties, differences in average prices and average cap rates may reflect differences in the mix of properties that transact in a particular period, especially for the smaller metropolitan areas.

Figure 1 summarizes the distribution of returns over our sample period for each of the four property types. At each time point, we display the cross-sectional mean and median returns together with their corresponding inter-quartile range which provides a measure of their dispersion. Consistent with a symmetric distribution, the mean and median returns do not appear to significantly deviate from one another. They do, however, vary over time with returns being on average appreciably higher after the mid-1990s. Consistent with the time-varying volatility of returns, the inter-quartile ranges for all property classes also vary over time. Similarly, Figure 2 summarizes the distribution of net rental growth rates over our sample period. For each of the property types, the net rental growth rates, on average, vary over time as do their corresponding inter-quartile ranges.

To further investigate the properties of these data, we compare the returns of the GRA aggregate series with the returns of corresponding NCREIF national indices which are based primarily on appraisal data. The series display similar patterns over our sample period. For example, the GRA and NCREIF series are highly correlated. These pairwise correlations range from about 0.7 for retail properties to about 0.9 for industrial properties. The means of the two series are also very similar. For offices, the corresponding mean returns are almost indistinguishable $(5.0 \%$ for the NCREIF data versus $4.6 \%$ for the GRA data), while for apartments the mean returns differ slightly $(8.5 \%$ for the NCREIF data versus $7.5 \%$ for the GRA data). In general, the average difference between the two return series is always small and never exceeds $1 \%$.

We estimate both $A R(1)$ and $A R(3)$ models to document the persistence of these alternative return series. The $A R(3)$ specification may be more appropriate at capturing short-term fluctuations in returns. The results from estimating these models suggest that the GRA returns series exhibit less persistence than the NCREIF returns series for all but apartments. For example, if we compare the sum of the first three $A R(3)$ coefficients for industrial properties and offices, the autocorrelation 
of the GRA data is much lower than that of the NCREIF data (1.839 versus 2.124 in the case of industrial properties and 1.660 versus 2.028 in the case of offices). This finding is consistent with the arguments in Geltner, Miller, Clayton, and Eichholtz (2000, Chap. 25) that transaction-based price indices exhibit less serial correlation than appraisal-based price indices.

\section{Macroeconomic Variables}

The state of the economy and financial markets at time $t$ is captured by a vector of variables denoted by $X_{t}$ which includes the term spread $\left(T S P R_{t}\right)$, the credit spread $\left(C S P R_{t}\right)$, the Consumer Price Index $(\mathrm{CPI})$ inflation rate $\left(I N F_{t}\right)$, and the three-month Treasury bill rate $\left(T B 3 M_{t}\right)$. These variables are widely used in the finance literature to summarize the state of the economy and to model the time-varying behavior of aggregate stock market expected returns (Campbell and Shiller (1988a), Campbell (1991), Fama and French (1989), Torous, Valkanov, and Yan (2005) and, for a good review, Campbell, Lo, and MacKinlay (1997)).

We use the term spread, defined as the difference between the yields on 10-year and 1-year Treasuries, to proxy for business cycle effects. As noted by Fama and French (1989), the term spread is closely related to shorter-term business cycles as identified by the National Bureau of Economic Research (NBER). Researchers have typically also relied upon the credit spread, calculated as the difference between the yields on BAA and AAA rated corporate bonds, as a business cycle proxy. However, since this variable is related to long-term business episodes that span several measured business cycles (Fama and French (1989)), the brevity of our sample period suggests that it would not be appropriate for us to interpret the credit spread as a business cycle proxy in our empirical analysis. Rather, given the importance of external debt financing to commercial real estate investment, we interpret this variable as a proxy for the availability of external debt financing, with narrow credit spreads corresponding to an abundance of this financing. The CPI inflation rate captures current economic activity while the three-month Treasury bill serves as a proxy for future economic activity. CPI inflation is defined as the quarterly growth rate in the CPI index. All these data, except the three-month Treasury bill rate, are taken from the FRED database. The three-month Treasury bill rate is obtained from Ibbotson Associates. 
We will rely on $X_{t}$ to investigate the extent to which the time variation in the cross-sectional dispersions of returns and growth in net rents can be explained by fluctuations in the overall state of the economy and conditions prevailing in financial markets.

\section{Cross-Sectional Dispersion of Excess Returns and Net Rental Growth Rates}

We denote by $R_{i, t+1}$ the return to a commercial property in metropolitan area $i$ at time $t+1$ measured in excess of the three-month Treasury bill rate. If there are $N_{t+1}$ metropolitan areas included in our data at time $t+1$, the cross-sectional dispersion of a given property type's return is

$S_{r, t+1}=\sqrt{\sum_{i=1}^{N_{t+1}}\left(R_{i, t+1}-\bar{R}_{t+1}\right)^{2} / N_{t+1}}$,

where $\bar{R}_{t+1}=N_{t+1}^{-1} \sum_{i=1}^{N_{t+1}} R_{i, t+1}$ is the property type's average return across metropolitan areas. Similarly, if $H_{t+1}$ represents a property's net operating income and $G H_{t+1}=\log \left(H_{t+1} / H_{t}\right)$ is its growth rate, then the cross-sectional dispersion of net rental growth rates is

$S_{g h, t+1}=\sqrt{\sum_{i=1}^{N_{t+1}}\left(G H_{i, t+1}-\overline{G H}_{t+1}\right)^{2} / N_{t+1}}$,

where $\overline{G H}_{t+1}=N_{t+1}^{-1} \sum_{i=1}^{N_{t+1}} G H_{i, t+1}$ is the property type's average growth in net rents across metropolitan areas. We estimate $S_{r, t+1}$ and $S_{g h, t+1}$ for each of the four property types - apartments, industrial, retail, and office properties. ${ }^{2}$

Panel A of Table 1 provides corresponding summary statistics of the cross-sectional dispersion estimates and the conditioning variables, all expressed on an annual basis. The average crosssectional dispersion of excess returns ranges from between $4.0 \%$ for retail properties to $7.0 \%$ for apartments. By way of comparison, the average annualized dispersion of monthly stock market returns is approximately 9.3\% (Goyal and Santa-Clara (2003)) while the corresponding average

\footnotetext{
${ }^{2}$ For simplicity of notation, when we refer to the cross-sectional variation of returns or growth in net rents for a particular property type, we will simply write $S_{r, t+1}$ or $S_{g h, t+1}$.
} 
annualized cross-sectional dispersion of the returns of Fama and French's forty-nine industry portfolios $^{3}$ is $15.7 \%$.

Our estimates of the dispersion of commercial real estate returns may be biased downwards for two reasons. First, in GRA's construction of metropolitan area data, some of the variability will have been diversified away. Second, the bi-annual commercial real estate data is much smoother than the stock market data which is measured at monthly or even daily frequencies. ${ }^{4}$

With regard to net rental growth rates, the average cross-sectional dispersion is between $3.5 \%$ for retail properties and $5.1 \%$ for offices and is consistently lower than the corresponding dispersion of returns. These estimates are also likely biased downwards for the same reasons the cross-sectional dispersion of returns estimates are. Taken together, our estimates should be viewed as lower bounds of $S_{r, t+1}$ and $S_{g h, t+1}$.

Turning to their time series properties, we find that these measures of cross-sectional dispersion fluctuate considerably over time, with standard deviations of between $1.2 \%$ and $2.5 \%$. These standard deviations lie between the volatilities of the macroeconomic variables, also displayed in Table 1, which range from $0.2 \%$ to $1.7 \%$, and the volatility of the cross-sectional dispersions of the Fama and French industry portfolios calculated to be approximately $6 \%$.

The $S_{r, t+1}$ series also exhibit considerable persistence with $A R(1)$ coefficients ranging from 0.259 for offices to as high as 0.748 for apartments. The $A R(1)$ coefficients of the $S_{g h, t+1}$ series range between 0.425 for offices to 0.707 for retail properties and are slightly less persistent, although not uniformly so across all property types. With the exception of the office series, both $S_{r, t+1}$ and $S_{g h, t+1}$ exhibit some skewness and little kurtosis.

The correlations between the measures of cross-sectional variation are displayed in Panel B of Table 1. Interestingly, the $S_{r, t+1}$ measures for the various property types are not highly correlated, while the $S_{g h, t+1}$ measures are even less correlated. However, for a given property type, the corresponding $S_{r, t+1}$ and $S_{g h, t+1}$ measures are themselves highly contemporaneously correlated. For instance, in the case of retail and offices, the pairwise correlations are 0.888 and 0.879 , respectively.

\footnotetext{
${ }^{3}$ Data are taken from Kenneth French's website. We sample these returns biannually to make this comparison more direct.

${ }^{4}$ Geltner (1993) discusses the effect of temporal aggregation on the dispersion of real estate returns.
} 
Figure 3 plots the times series of $S_{r, t+1}$ and $S_{g h, t+1}$ for each of the four property types. As expected, we see that the dispersion of returns (solid line) is almost always greater than the dispersion of net rental growth (dashed line). The graphs show that returns and net rental growth appear to be heteroskedastic. In the case of apartments, office, and industrial properties, the $S_{r, t+1}$ and $S_{g h, t+1}$ series vary substantially and exhibit clusters of particularly high dispersion which is a hallmark of heteroskedastic processes. This observation is consistent with the corresponding large $A R(1)$ coefficients in Table 1. We see that for apartments and industrial properties, the dispersions increase in 1993-94, whereas for offices dispersions increase during the 1997-98 period. ${ }^{5}$

To summarize, the cross-sectional dispersions of commercial real estate returns and net rental growth rates are less volatile than stock market returns. These cross-sectional dispersions are time-varying and exhibit serial correlation. The autocorrelations of $S_{r, t+1}$ and $S_{g h, t+1}$ are not as large as would be expected if they were driven solely by very low frequency fluctuations arising from demographic or urbanization trends. In fact, their time series properties are similar to those of economic variables often used in the finance literature to proxy for the state of the economy. Hence, the observed variations in our cross-sectional dispersion measures may be due to changes in underlying economic conditions, which is the hypothesis that we investigate next.

\section{Links Between Cross-Sectional Dispersions and Economic Variables}

Commercial real estate prices are dependent upon underlying economic conditions. For example, an economic downturn with a corresponding reduction in employment and production lessens the demand for commercial real estate which, in turn, directly affects occupancy and lease rates. Overall economic conditions also affect the supply of commercial real estate. A downturn in the economy will result in fewer construction starts together with a slowdown in current construction as builders wait for a recovery to dispose of their properties. ${ }^{6}$

Another link between commercial property valuations and the economy operates through the banking sector. A change in monetary policy which changes the cost of funds to banks tends to change the external finance premium faced by commercial real estate investors in the same

\footnotetext{
${ }^{5}$ We verified that these large increases in dispersions are not driven by any one, two, or three outliers.

${ }^{6}$ Case and Shiller (1989) make a similar argument for the housing market.
} 
direction (Bernanke (1983), Bernanke and Blinder (1988)). As a result, during tight money periods when interest rates rise, credit terms become relatively more onerous, thereby adversely affecting commercial real estate valuations.

In this section, we investigate the links between underlying economic conditions and the crosssectional dispersions of commercial real estate returns and growth rates in net rents. We demonstrate that a significant fraction of the previously documented time series variation in crosssectional dispersions is correlated with lagged macroeconomic variables. This result is not surprising in light of the extant empirical evidence showing that macroeconomic fluctuations influence the cross-section of commercial real estate values. For example, the effects of macroeconomic fluctuations and their speeds of propagation differ across metropolitan areas. These differences depend on several factors, including differences in the composition of local industry, the distribution of firm sizes, as well as differences in the availability of funds across regions. Carlino and DeFina (2003) demonstrate that, in general, differences in industry composition are substantial and can lead to dramatic economic effects. Empirically, Carlino and Sill (2001) find considerable differences in the volatility of regional business cycles, while Owyang, Piger, and Wall (2003) document that both the depth of a recession and the speed of a recovery vary across states. In addition, Fratantoni and Schuh (2003) provide evidence that the effects of a Federal Reserve monetary policy shock differ across real estate markets while Owyang and Wall (2004)) empirically relate these differences to differences in industrial composition and to differences in firm size.

\section{Economic Shocks}

To investigate whether changes in economic conditions systematically affect the cross-sectional dispersions of returns and growth rates in net rents, we run the following pair of regressions for each property type:

$$
\begin{aligned}
S_{r, t+1} & =\kappa_{r}+\gamma_{r} X_{t}+\phi_{r} S_{r, t}+\varepsilon_{r, t+1} \\
S_{g h, t+1} & =\kappa_{g h}+\gamma_{g h} X_{t}+\phi_{g h} S_{g h, t}+\varepsilon_{g h, t+1} .
\end{aligned}
$$


The parameters $\gamma_{r}$ and $\gamma_{g h}$ measure the sensitivities of the cross-sectional dispersions of returns and growth rates in net rents, respectively, to lagged values of the macroeconomic variables $X_{t}$. We lag the macroeconomic variables to prevent simultaneity problems. Since these variables are persistent, it is well known that the estimates of $\gamma_{r}$ and $\gamma_{g h}$ will be biased in the presence of any correlation between innovations in $X_{t}$ and the cross-sectional dispersion measures (Stambaugh (1999)). ${ }^{7}$

An autoregressive term is included in these regressions to capture any time series variation in $S_{r}$ and $S_{g h}$ attributable to factors other than prevailing macroeconomic conditions. These factors include geographic, demographic, and urbanization trends, as well as idiosyncratic shocks. Several authors provide evidence of time series variation in real estate prices and rents due to such factors. For example, Abraham and Hendershott (1996) document significant differences in the time series properties of residential real estate prices in coastal versus inland U.S. cities, while Plazzi, Torous, and Valkanov (2004) find similar effects for commercial properties. If coastal properties become more valuable over time, then the cross-sectional dispersion of returns will change. Similarly, demographic effects, such as immigration to specific regions, may result in a change in the crosssectional dispersions of returns and rents over time.

In estimating the pair of regressions (3) and (4), it is unrealistic to believe that the resultant errors will be uncorrelated. This being the case, we assume that the contemporaneous cross-equation error correlations for each property type are non-zero and estimate expressions (3) and (4) by property type using seemingly unrelated regression (SUR). ${ }^{8}$ Because of our small sample size, we do not rely on standard asymptotics even though the dependent variables $S_{r}$ and $S_{g h}$ are close to being normally distributed..$^{9}$

Table 2 shows the SUR results. There we provide bias-adjusted estimated coefficients and $p$-values

\footnotetext{
${ }^{7}$ Our bootstrapped standard errors, discussed later, will take any resultant bias into account. Note that Stambaugh's bias adjustment is possible for only one predictor.

${ }^{8}$ Alternatively, we could have grouped the regressions by explanatory variable resulting in two systems of four regressions in each of $S_{r}$ and $S_{g h}$. However, the resultant variance-covariance matrices will be inefficiently estimated because of our limited number of observations, thereby worsening the precision of these SUR estimates.

${ }^{9}$ For example, relying on the Jarque-Bera statistics presented in Table 1, we cannot reject that $S_{g h}$ is normally distributed for each of the commercial property types. We cannot reject the normality of $S_{r}$ for industrial and retail properties but can reject this null hypothesis in the case of apartments and offices. By contrast, we can reject that the cross-sectional variance of returns, $S_{r}^{2}$, and variance of net rent growth, $S_{g h}^{2}$, are normally distributed for all property types except retail.
} 
based on bootstrapping that will be relied upon to assess statistical significance. ${ }^{10}$ In Panel A, we consider specifications of expression (3) in which the autoregressive term is excluded as well as included. The term spread (TSPR) enters each regression with a positive sign. Moreover, it is significant at the $5 \%$ level or better for all property types with the exception of retail when lagged $S_{r, t+1}$ is included. The credit spread (CSPR) enters each regression with a negative sign and is significant at the $5 \%$ level or better for all property types except retail. The three-month Treasury bill rate (TB3M) has a positive effect on $S_{r, t+1}$ for all property types but is only significant for apartments when lagged $S_{r, t+1}$ is excluded. Inflation (INF) has a negative effect on the dispersion of excess returns of apartments and offices. However, this effect is statistically significant only in the case of offices when lagged $S_{r, t+1}$ is excluded. Inflation does not play a statistically significant role in explaining the dispersion of excess returns of industrial and retail properties. ${ }^{11}$ Finally, lagged $S_{r, t+1}$ (LAG) is found to be significant at the $5 \%$ level or better for all property types except offices. This is in agreement with the $A R(1)$ coefficients reported in Table 1 where offices are the only property type which does not exhibit significant autocorrelation.

The results of estimating regression (4) for all property types are displayed in Panel B of Table 2. As before, we consider specifications in which the autoregressive term is excluded as well as included. The term spread (TSPR) enters each regression with a positive sign and is statistically significant at the $5 \%$ level or better for all property types with the exception of retail when lagged $S_{g h, t+1}$ is included. However, the term spread coefficients are now seen to be much smaller in magnitude when compared to their counterparts in Panel A. The credit spread (CSPR) enters each regression with a negative sign but, once again, the coefficients are seen to be smaller in magnitude and their statistical significance is diminished. Similar conclusions apply to the coefficient estimates of TB3M and CPI with their signs generally agreeing with those in the dispersion of returns equations, but

\footnotetext{
${ }^{10}$ To do so, we store the residuals from estimating the regressions by property type using SUR. We then generate time series of dispersions under the null hypothesis that the corresponding slope coefficients are zero by randomizing these residuals with replacement making sure to maintain the prevailing cross-equation correlation by taking residuals of both equations from the same position. We then regress the resultant series on the lagged economic variables as well as lagged dispersions to calculate bootstrapped slope coefficient estimates. We repeat this procedure $N=5000$ times to obtain an empirical distribution of each slope coefficient under the null hypothesis. The average of each empirical distribution is a measure of the small-sample bias suffered by the SUR estimator. We report bias-adjusted slope coefficients by subtracting this measure of small-sample bias from the corresponding SUR estimates.

${ }^{11}$ The absence of a statistically significant impact of the Treasury bill rate and of the inflation measure can be partly reconciled with the fact that our cross-sectional dispersion measure is constructed using excess returns.
} 
their magnitudes now being somewhat smaller. Interestingly, the coefficients throughout Table 2 are, in general, consistent across property types, indicating that overall economic fluctuations have a systematic effect on the dispersion of commercial real estate returns and net rental growth rates. The signs of the term spread coefficient in these regressions imply that both expected $S_{r, t+1}$ and $S_{g h, t+1}$ are high in periods when the term spread is wide. Since it is well documented that the term spread tends to widen in a business cycle downturn (e.g., Fama and French (1989), Campbell, Lo, and MacKinlay (1997)), the evidence in Table 2 suggests that the expected values of $S_{r, t+1}$ and $S_{g h, t+1}$ behave counter-cyclically. In other words, the cross-sectional dispersions of returns and net rental growth rates are largest in a recession and smallest in an expansion. ${ }^{12}$ Conversely, both $S_{r, t}$ and $S_{g h, t}$ are expected to be low in periods when the credit spread is wide. The widening of the credit spread, consistent with tightening conditions in credit markets and more expensive external debt financing, results not only in lower commercial real estate valuations but is seen to also reduce the cross-sectional dispersions of returns and net rental growth rates.

The regression estimates of Table 2 are consistent with the macroeconomic variables having an economically meaningful effect on the cross-sectional dispersions ${ }^{13}$. The economic impact of the macroeconomic variables is easy to interpret since the left- and right-hand side variables of these regressions are both expressed in percentages. For example, in Panel A, from the first specification that excludes the lagged dispersion for apartments, we see that a two standard deviation increase in the term spread is associated with a $4.4 \%(2 \times 1.1 \times 2.077)$ subsequent increase in the cross sectional dispersion of apartment returns, ${ }^{14}$ which represents a $62.8 \%$ increase relative to this dispersion's unconditional mean of $7 \%$ (from Table 1).

Table 3 displays the marginal economic significance of all the variables across property types. In each case, the first entry is the variable's economic significance computed as two times the standard

\footnotetext{
${ }^{12}$ Schwert ((1989), (1990)) observes the same counter-cyclical behavior in aggregate stock market volatility.

${ }^{13}$ We also tried using national real GDP growth and national employment growth as control variables, but found no statistically significant impact on our cross-sectional measures. Since there are strong economic reasons to believe that cross-sectional dispersions vary with business cycle conditions, we attribute this lack of significance to measurement errors and noisiness in these economic variables. Ideally, one would like to test whether the cross-sectional dispersion in GDP growth and employment growth are related to the dispersion in real estate valuations, as our discussion in the previous section suggests. Unfortunately, biannual data on GDP and employment are not available for the areas and sample periods we are analyzing.

${ }^{14}$ The standard deviations of the macroeconomic variables are from Table 1.
} 
error of the regressor times its coefficient and corresponds to the response of the dispersion to a two standard deviation shock in the underlying variable. The second entry is the absolute value of the response divided by the average dispersion and represents the marginal response as a fraction of the dispersion.

The results in Table 3 show that the term spread captures the largest fraction of the variation in $S_{r, t+1}$. Across property types, a two standard deviation shock to the term spread in the first specification results in an increase in $S_{r, t+1}$ of between $1.3 \%$ (retail) and $4.4 \%$ (apartments). This corresponds to between $31.4 \%$ and $62.8 \%$ of the total variability of $S_{r, t+1}$. The credit spread and the Treasury bill rate also appear to have an economically important effect in the first specification, while inflation is only economically important for office properties. We observe similar results for the $S_{g h, t+1}$ regressions.

As previously conjectured, the observed effects of the economic variables on the cross-sectional variations of returns and net rental growth rates are consistent with differences in the propagation of economic shocks across regions. Alternatively, there may be cross-sectional differences in the characteristics of the commercial properties that would lead to fluctuations in the cross-sectional dispersions of returns and net rental growth rates even in the absence of a differential propagation of economic shocks. We elaborate on and test a variant of this hypothesis in the next section.

\section{Leverage and Asymmetric Cross-Sectional Dispersion}

To the extent that the degree of leverage varies across regions, economic shocks can affect the crosssection of commercial real estate valuations even if these shocks are propagated uniformly across regions. To see this, suppose that the same negative shock impacts two metropolitan areas, and that office properties are leveraged in one area but not in the other. As argued by Bernanke and Gertler (1989), Bernanke, Lown, and Friedman (1991) and summarized by Bernanke and Gertler (1995), this negative shock amplifies existing frictions in credit markets arising from asymmetric information and the costly enforcement of contracts and results in an increase in the premium on external debt financing. All else being equal, the valuations of office properties located in the metropolitan area relying on debt financing are adversely affected owing to their reliance on the 
now more expensive debt capital. The costlier nature of debt financing would also reduce net operating income (NOI) and so adversely affect the growth rate in net rents. As a result, the cross-sectional dispersions of returns and net rental growth rates across the two metropolitan areas will increase in response to this negative shock. Similarly, a positive economic shock also increases these cross-sectional dispersions as office properties in the leveraged metropolitan area now benefit from the less expensive debt capital. However, as negative shocks tend to be significantly sharper than positive economic shocks, ${ }^{15}$ this leverage effect introduces an asymmetry into the response of the cross-sectional dispersions to economic shocks. Negative shocks will result in a larger increase in the cross-sectional dispersions $S_{r, t+1}$ and $S_{g h, t+1}$ than positive shocks.

Black discusses a similar hypothesis related to leverage which is often invoked to explain asymmetries in the time series volatility of equities. ${ }^{16}$ Some researchers, however, have questioned the relevance of Black's argument in light of the relatively low levels of leverage in the stock market (for example, Christie (1982), Schwert (1989), and for a review, Campbell, Lo, and MacKinlay (1997, p.497)).

In contrast to equities, investment in real estate, residential as well as commercial, is characterized by a greater reliance on leverage and so is potentially more likely to exhibit leverage effects. In the case of residential real estate, Lamont and Stein (1999) demonstrate that leverage varies across metropolitan areas and that the effects of an economic shock on housing increases with leverage and can be sizable. While the GRA data do not provide information on leverage, we expect the degree of leverage in commercial real estate investments to also vary across metropolitan areas. For example, Malpezzi and Shilling (2000) show that because of their fiduciary responsibilities, institutional investors tilt more of their commercial real estate holdings towards less speculative regions than public investors do. ${ }^{17}$ Similarly, Mahoney, McCarron, Miles, and Sirmans (1996) document that institutional investment in commercial real estate is more locationally concentrated than public

\footnotetext{
${ }^{15}$ This asymmetry has been extensively documented and modeled in the macroeconomic literature. See, for example, Neftci (1984), Hamilton (1989), Diebold and Rudebusch ((1990a),(1990b)), Sichel (1993) and Acemoglu and Scott (1997).

${ }^{16}$ It should be noted that Black's hypothesis does not rely on imperfections in external capital markets and cannot generate cross-sectional asymmetries.

${ }^{17}$ Location serves as a proxy for property quality. High quality commercial real estate is assumed to be located in less speculative regions characterized by being large, high growth, high income and low variance metropolitan areas.
} 
commercial real estate investment. Since institutional investors rely on less debt financing, these locational differences suggest that the degree of leverage in commercial real estate also varies crosssectionally.

If leverage varies across metropolitan areas then we would expect to observe an asymmetric response in the cross-sectional dispersions to economic shocks. To measure economic shocks, we rely on the Chicago Fed National Activity Index (CFNAI), a monthly coincident indicator of broad-based economic activity originated by Stock and Watson (1999). ${ }^{18}$ In particular, a negative economic shock is identified in a six-month period when the average of the corresponding six monthly CFNAI observations is negative. To investigate whether the cross-sectional dispersions respond asymmetrically to economic shocks, we modify our preceding regressions to include a dummy variable, $d_{t}$, which takes on the average value of the CFNAI index during a negative shock and is zero otherwise:

$$
\begin{aligned}
S_{r, t+1} & =\kappa_{r}+\gamma_{r} X_{t}+\phi_{r} S_{r, t}+\delta_{r} d_{t}+\varepsilon_{r, t+1} \\
S_{g h, t+1} & =\kappa_{g h}+\gamma_{g h} X_{t}+\phi_{g h} S_{g h, t}+\delta_{g h} d_{t}+\varepsilon_{g h, t+1} .
\end{aligned}
$$

The coefficients $\delta_{r}$ and $\delta_{g h}$ capture the presence of this asymmetry with the estimates being interpreted as the difference in the corresponding cross-sectional dispersions following a negative shock. ${ }^{19}$ We once again include the macroeconomic variables $X_{t}$ to control for time variation in the state of the economy.

Table 4 reports the results of estimating regressions (5) and (6). The coefficient estimates on the dummy variable are always positive, implying that negative shocks have a larger effect on the dispersions. In the $S_{r, t+1}$ regressions, these coefficients are significant at the $5 \%$ level or better in the case of apartments and retail properties. For these property types, the inclusion of the dummy variable results in a substantial increase in the goodness of fit as measured by the $R_{a d j}^{2}$ statistic. In the $S_{g h, t+1}$ regressions, the coefficients on the dummy variable are still positive, but are just

\footnotetext{
${ }^{18}$ This index is based on the first principal component of 85 economic activity series and is constructed to have an average value of zero and a standard deviation of one. Since economic activity tends to grow at a trend, an index reading of zero corresponds to the economy growing at trend.

${ }^{19}$ Equations (5) and (6) are similar to Glosten, Jagannathan, and Runkle's (1993) test for asymmetry in systematic risk measures, but in the present context, we consider asymmetries in the cross-sectional dispersions.
} 
marginally significant for retail properties.

\section{Robustness checks}

\section{Robust Measures of Dispersion}

Our previous results rely upon the standard deviation to measure the cross-sectional dispersion of both returns and net rental growth rates. While the use of the standard deviation has many advantages and allows us to interpret the results in terms of percentages, because it is evaluated using squared deviations from the average, the standard deviation has the drawback that its value is extremely sensitive to outliers. Since only twenty-one metropolitan areas are included during the first two years of our sample period, it is important to investigate whether our results are capturing a truly time-varying phenomenon or are, instead, being driven by a few outliers in small samples. This latter possibility could arise, for example, if returns in a few areas are affected by persistent idiosyncratic shocks that drive these returns away from their long-run means. As a result, both the kurtosis of the sample returns as well as the cross-sectional dispersion as measured by the standard deviation would increase.

In order to control for the presence of outliers, we define an alternative measure of dispersion for excess returns:

$V_{r, t+1}=\sqrt{\sum_{i=1}^{N_{t+1}}\left|R_{i, t+1}-\bar{R}_{t+1}\right| / N_{t+1}}$

and similarly for the net rental growth rate:

$V_{g h, t+1}=\sqrt{\sum_{i=1}^{N_{t+1}}\left|G H_{i, t+1}-\overline{G H}_{t+1}\right| / N_{t+1}}$

both of which rely on the absolute value as a measure of distance as opposed to the quadratic function. These "absolute dispersion" measures will be less susceptible to any outliers.

To test the impact of outliers, we re-estimate regressions (3) and (4) using the absolute dispersion measures and present the results in Table 5. When compared to our previous results, we see 
that our conclusions are unaltered. For example, the economic variables remain significant with the term and credit spreads being the most significant explanatory variables. The signs of these estimated coefficients are, as before, consistent with the cross-sectional dispersion measures being counter-cyclical and varying inversely with the credit spread. The regression $R_{a d j}^{2}$ s are also seen to be similar in magnitude to those previously reported.

Table 6 provides the results of estimating the regressions (5) and (6) when using the absolute dispersion measures in the presence of asymmetries. Once again, we see that the use of an alternative dispersion measure does not alter our previous findings. The dummy variable enters the regressions with a statistically significant positive coefficient for the same properties as in Table 4. Its inclusion leads to a general increase in the $R_{a d j}^{2}$ statistic with retail, once again, displaying the highest increase in goodness of fit. As before, the inclusion of the dummy variable does not change the statistical significance of the conditioning variables which display essentially the same magnitudes and $t$-statistics as in Table 5 .

\section{Alternative Portfolio Weights}

The number of MSAs in our sample increases from twenty-one in 1986 to fifty-eight in 2002. The added MSAs tend to be smaller, hence the corresponding prices and cap rates are likely to be calculated based on fewer transactions. This suggests that their average returns and average net rental growth rates might be measured with greater error. Because we equally weight the MSAs when constructing the cross-sectional dispersion measures, spurious temporal behavior in the measures could result.

To investigate the impact of this possibility on our empirical results, we construct alternative measures of cross-sectional dispersion based on a weighting scheme which gives larger weights to MSAs where average returns and average net rental growth rates are estimated with smaller sampling error. In order to directly compare these results with our previous tables, we normalize the sum of the weights to unity in each period. In particular, if we denote the inverse of the sampling variance of the average return and average net rental growth rate in area $i$ by $\lambda_{r, i}$ and $\lambda_{g h, i}$, respectively, the new weighted measure of the cross-sectional dispersion of returns is given 
by:

$S_{r, t+1}^{w}=\sqrt{\sum_{i=1}^{N_{t+1}} \frac{\lambda_{r, i}}{\sum_{i=1}^{N_{t+1}} \lambda_{r, i}}\left(R_{i, t+1}-\bar{R}_{t+1}\right)^{2} / N_{t+1}}$

while the new weighted measure of the cross-sectional dispersion of net rental growth rates is:

$S_{g h, t+1}^{w}=\sqrt{\sum_{i=1}^{N_{t+1}} \frac{\lambda_{g h, i}}{\sum_{i=1}^{N_{t+1}} \lambda_{g h, i}}\left(G H_{i, t+1}-\overline{G H}_{t+1}\right)^{2} / N_{t+1} .}$

The new measures are highly correlated with the corresponding measures based on equal weighting, the pairwise correlations being in the range of between 0.95 to 0.99. As expected, with reference to Table 7, we see that using these new cross-sectional dispersion measures when re-estimating the regressions (3) and (4) does not appreciably alter our conclusions. ${ }^{20}$

\section{Expected Returns and the Cross-Sectional Variation of Returns}

Diversification is made more difficult for commercial real estate than other assets because commercial real estate is inherently illiquid, cannot be shorted and is often privately held. This suggests that investors will demand to be compensated for exposure to commercial real estate's total risk.

To understand the role of the cross-sectional dispersion of commercial real estate returns, $S_{r, t+1}$, in assessing this total risk-return tradeoff, square expression (1) which after simplification gives:

$S_{r, t+1}^{2}=\frac{1}{N_{t+1}} \sum_{i=1}^{N_{t+1}} R_{i, t+1}^{2}-\bar{R}_{t+1}^{2}$

Assuming that variance can be adequately approximated by squared returns, the first term on the right-hand side of the preceding expression gives the average variance of, say, office property returns at time $t+1$, while the second term gives the corresponding variance of the return to an equallyweighted portfolio of office properties. Average variance is a measure of total risk, including both

\footnotetext{
${ }^{20}$ We also tried an alternative weighting scheme where the weights are proportional to the MSA's population and again obtained very similar results.
} 
market-wide and idiosyncratic components, while the variance of an equally-weighted portfolio measures only market-wide risk. The cross-sectional dispersion of office returns, therefore, is a measure of idiosyncratic risk. Intuitively, cross-sectional dispersion in office returns must be driven by idiosyncratic shocks. However, to the extent that the market-wide risk exposure is relatively small, the squared cross-sectional dispersion, $S_{r, t+1}^{2}$ should accurately proxy average variance. In fact, for our commercial real estate returns data, $S_{r, t+1}^{2}$ and average variance are highly correlated. ${ }^{21}$ This implies that we can also view the squared cross-sectional dispersion of returns as a measure of the average variance of commercial real estate returns ${ }^{22}$, meaning that we can rely upon $S_{r, t+1}^{2}$ to investigate the nature of the total risk-return tradeoff in these markets.

From a different perspective, consider an investor who owns a particular property, again, say, an office building, in metropolitan area $i$. The investor is personally confronted with the following total risk-return trade-off

$R_{i, t+1}=\alpha+\psi R_{i, t}^{2}+\varepsilon_{t+1}$

where the total risk of office returns in area $i$ is proxied by the squared office returns in area $i$. The slope coefficient $\psi$ measures the sensitivity of office returns to their total risk and is assumed to be constant across metropolitan areas. In other words, different metropolitan areas differ in the total risk of office returns but not in the sensitivity of these returns to their total risk. In this case, however, a more precise estimate of $\psi$ can be obtained by regressing the average of office returns across different metropolitan areas, $\bar{R}_{t+1} \equiv N_{t+1}^{-1} \sum_{i=1}^{N_{t+1}} R_{i, t+1}$, against the corresponding average variance of office returns, $N_{t+1}^{-1} \sum_{i=1}^{N_{t+1}} R_{i, t+1}^{2}$, or, since the average variance is mostly idiosyncratic, against the squared cross-sectional dispersion of office returns $S_{r, t+1}^{2}$

$\bar{R}_{t+1}=\alpha+\psi S_{r, t+1}^{2}+\varepsilon_{t+1}$.

To test the total risk-return trade-off hypothesis in commercial real estate, we estimate the following

\footnotetext{
${ }^{21}$ In particular, the correlation between $S_{r, t+1}^{2}$ and $\frac{1}{N_{t+1}} \sum_{i=1}^{N_{t+1}} R_{i, t+1}^{2}$ is 0.86 for apartments, 0.82 for industrial properties, 0.64 for retail properties and 0.90 for office properties.

${ }^{22}$ This argument follows that of Goyal and Santa-Clara (2003) who in the context of stock returns show that the cross-sectional variance of stock returns proxies their mostly idiosyncratic average.
} 
regression across property types using SUR:

$\bar{R}_{t+1}=\alpha+\beta R_{t+1}^{M}+\psi S_{r, t}^{2}+\varepsilon_{t+1}$

where $\bar{R}_{t+1}$ is the annualized return to an equally-weighted portfolio in the property type across regions, $R_{t+1}^{M}$ is the return of the aggregate stock market as proxied by the return of the Center for Research in Security Prices' (CRSP) value-weighted (VW) portfolio, and $S_{r, t}^{2}$ is the corresponding cross-sectional variance of the property type's returns. ${ }^{23}$ Within a Merton (1973) ICAPM framework, regression (11) implies that, in addition to market risk, total risk is also a risk factor. A priori, we expect the $\psi$ estimates to be positive if investors demand higher commercial real estate returns in periods when their variance is higher. In addition, we expect the $\beta$ estimates to be close to zero as it is well known that real estate investments have low systematic risk when measured with respect to the stock market (Case and Shiller (1989), Case (2000), Chiang, Kozhevnikov, Lee, and Wisen (2006)).

The first Panel of Table 8 displays the results of estimating regression (11). Notice that the $\psi$ estimates are all positive and statistically different from zero at better than the $5 \%$ significance level for all property types except industrial where the estimated $\psi$ coefficient is different from zero at nearly the $10 \%$ significance level. By contrast, the $\beta$ estimates are all statistically indistinguishable from zero at conventional significance levels. These findings are consistent with a positive total riskreturn relation in the commercial real estate market and the absence of any correlation between commercial real estate returns and stock market returns.

Regressions that estimate the relation between total risk and returns in equity markets usually do not find a positive nor statistically significant coefficient. ${ }^{24}$ Recently, Ghysels, Santa-Clara, and Valkanov (2004) document a statistically significant positive total risk-return relation for the aggregate stock market. They show that in regressions such as (11), it is important to have a

\footnotetext{
${ }^{23}$ We use the variance rather than the standard deviation as this is the customary specification in the risk-return literature (Merton (1980), French, Schwert, and Stambaugh (1987), Engle, Lilien, and Robins (1987), Ghysels, SantaClara, and Valkanov (2004)). Using the standard deviation gives very similar results (omitted for brevity).

${ }^{24}$ For example, Campbell (1987), French, Schwert, and Stambaugh (1987), Turner, Startz, and Nelson (1989), Baillie and DeGennaro (1990), Campbell and Hentschel (1992), Glosten, Jagannathan, and Runkle (1993), and Whitelaw (1994).
} 
sufficiently long forecasting horizon to proxy for expected returns. In our case, six-month returns appear to be a good proxy for commercial real estate expected returns.

Alternatively, it may be argued that these regression results are not due to the pricing of total risk in commercial real estate markets but rather reflect time-varying expected returns for commercial real estate. Campbell and Shiller (1988b), Fama and French (1989), Keim and Stambaugh (1986) and others show that expected returns of stocks and bonds vary with the state of the economy while Plazzi, Torous, and Valkanov (2004) document the same result for commercial real estate. If, as previously documented, $S_{r, t}^{2}$ also varies with the state of the economy, then these regression results may simply be due to the cross-sectional variation in returns proxying for time variation in the economy. Under this argument, directly adding economic variables that proxy for business cycle fluctuations to regression (11) would render the coefficient on $S_{r, t}^{2}$ insignificant. A related argument for including these additional economic variables is provided by Scruggs (1998) who shows that it is important in an ICAPM setting to include all variables that characterize changes in the investment opportunity set. Otherwise, regressions such as (11) will suffer from omitted variables bias ${ }^{25}$.

To address these issues, we run the following regression

$\bar{R}_{t+1}=\alpha+\beta R_{t}^{M}+\psi S_{r, t}^{2}+\chi Z_{t}+\varepsilon_{t+1}$

where $Z_{t}$ is a set of conditioning information. Following Scruggs (1998), we rely on the long-term Treasury yield as the additional state variable. ${ }^{26}$

These regression results are shown for all property types in the second panel of Table 8. Notice that conditioning on long-term Treasury yields has little effect on the $\psi$ estimates. While slightly attenuated, they are all positive and in the case of apartments, retail properties and offices, are statistically different from zero at the $10 \%$ significance level or better.

In summary, we find a positive and statistically significant relation between commercial real estate

\footnotetext{
${ }^{25}$ Another possibility is that our results are due to returns and the variance measure both being persistent and the correlation between the two being spurious as a result. We control for this possibility by including lagged returns in the regression and find that its inclusion, although statistically significant, does not alter the significance of the variance measure. Results are omitted for brevity.

${ }^{26}$ We also tried the term spread, inflation, and the three-month Treasury bill rate, but they were insignificant and the estimates of $\psi$ were very similar.
} 
returns and their cross-sectional dispersion. This relation does not appear to be merely proxying for fluctuations in the state of the economy. Given the small sample size, the statistical significance of these results is quite encouraging.

\section{Conclusions}

This paper investigates the cross-sectional dispersions of commercial real estate returns and net rental growth rates. Relying on data from a number of U.S. metropolitan areas over the 1986-2002 sample period, we analyze the time-series properties of these dispersions for apartments, industrial, retail, and office properties. The dispersions are found to be time-varying and persistent, and more importantly, their fluctuations are forecasted by the term and credit spreads. In particular, the cross-sectional dispersions are counter-cyclical, increasing in recessions and decreasing in expansions, and vary inversely with the credit spread, decreasing when credit spreads widen with tightening conditions in credit markets. Cross-sectional dispersions also respond asymmetrically to economic shocks, increasing more in response to negative shocks than positive shocks. We would expect to observe this asymmetry if the degree of leverage used to finance commercial real estate varies across metropolitan areas.

The fluctuations in the cross-sectional dispersions are positively related to subsequent commercial real estate returns. This is consistent with investors expecting higher returns to commercial real estate in periods of high total risk. Investors demand compensation for being exposed to total risk as most of this dispersion is difficult to diversify in commercial real estate markets.

This paper raises several additional issues. Firstly, while the fluctuations of the cross-sectional dispersions are seen to be linked to prevailing aggregate economic conditions, we do not provide direct evidence as to the transmission mechanism by which macroeconomic shocks are propagated to regional commercial real estate markets. Similarly, while the asymmetric response of the crosssectional dispersions is consistent with the leverage conjecture, we provide only indirect evidence in support of this hypothesis. An interesting direction for future research would be to design more direct tests of these economic mechanisms using disaggregated data which, unfortunately, is not currently available. 
Another interesting question is whether a positive relation between total risk and return is present in the market for real estate investment trusts (REITs). One of the most important benefits of REITs is that they allow investors to hold a more diversified commercial real estate portfolio. To the extent that our results are driven by the difficulty to diversify, the results in the REIT market should be weaker.

Finally the results presented in this paper underscore the importance of heterogeneity in understanding commercial real estate markets. This heterogeneity makes the valuation of commercial real estate much more difficult than the valuation of other assets trading in more liquid markets. Hopefully, the findings in this paper will stimulate future work on this important issue.

\section{Acknowledgments}

We thank Bob Edelstein, Jeff Fisher, Amit Goyal, Harrison Hong, Norm Miller, Pedro SantaClara and William Wheaton for helpful discussions, and three referees for helpful comments on earlier drafts. Valkanov acknowledged financial support from an UCLA Academic Senate grant. All remaining errors are our own.

\section{References}

Abraham, Jesse M., and Patric H.. Hendershott, 1996, Bubbles in Metropolitan Housing Markets, Journal of Housing Research 7, 191-207.

Acemoglu, Daron, and Andrew Scott, 1997, Asymmetric Business Cycles: Theory and Time Series Evidence, Journal of Monetary Economics 40, 501-533.

Baillie, Richard T., and Ramon P. DeGennaro, 1990, Stock Returns and Volatility, Journal of Financial and Quantitative Analysis 25, 203-214. 
Bernanke, Ben S., 1983, Nonmonetary Effects of the Financial Crisis in Propagation of the Great Depression., American Economic Review 73, 257-276.

— , and Alan S. Blinder, 1988, Credit, Money and Aggregate Demand., American Economic Review 78, 435-439.

Bernanke, Ben S., and Mark Gertler, 1989, Agency Costs, Net Worth, and Business Fluctuations, American Economic Review 79, 14-31.

— 1995, Inside the Black Box: The Credit Channel of Monetary Policy Transmission, Journal of Economic Perspectives 9, 27-48.

Bernanke, Ben S., Cara Lown, and Benjamin Friedman, 1991, The Credit Crunch, Brooking Papers on Economic Activity 2, 205-247.

Black, Fischer, 1976, Studies in Stock Price Volatility Changes, in Proceedings of American Statistical Association, Business and Economic Statistics Section pp. 177-181.

Bollerslev, Tim, Ray Chou, and Kenneth Kroner, 1992, ARCH Modeling in Finance: A Review of the Theory and Empirical Evidence, Journal of Econometrics 52, 5-59.

Campbell, John, Martin Lettau, Burton Malkiel, and Yexiao Xu, 2001, Have Individual Stocks Become More Volatile? An Empirical Exploration of Idiosyncratic Risk, Journal of Finance 56, $1-44$.

Campbell, John, Andrew Lo, and Craig MacKinlay, 1997, The Econometrics of Financial Markets (Princeton University Press: Princeton, NJ).

Campbell, John Y., 1987, Stock Returns and the Term Structure, Journal of Financial Economics 18, 373-399.

— , 1991, A Variance Decomposition for Stock Returns, Economic Journal 101, 157-179.

— , and Ludger Hentschel, 1992, No News is Good News: An Asymmetric Model of Changing Volatility in Stock Returns, Journal of Financial Economics 31, 281-318. 
Campbell, John Y., and Robert J. Shiller, 1988a, Stock Prices, Earnings, and Expected Dividends, Journal of Finance 43, 661-676.

— 1988b, The Dividend-Price Ratio and Expectation of Future Dividends and Discount Factors, Review of Financial Studies 1, 195-228.

Carlino, Gerald A., and Robert H. DeFina, 2003, How Strong is Co-Movement in Employment over the Business Cycle? Evidence from State/Industry Data, Federal Reserve Bank of Philadelphia Working Paper.

Carlino, Gerald A., and Keith Sill, 2001, Regional Income Fluctuations: Common Trends and Common Cycles, Review of Economics and Statistics 83, 446-456.

Case, Karl E., 2000, Real Estate and the Macroeconomy, Brookings Papers on Economic Activity 2, 119-162.

— , and Robert. Shiller, 1989, The Efficiency of the Market for Single-Family Homes, American Economic Review 79, 125-137.

Chiang, Kevin C.H., Kirill Kozhevnikov, Ming-Long Lee, and Craig H. Wisen, 2006, REIT Mimicking Portfolio Analysis, International Real Estate Review 9, 95-111.

Christie, Andrew A., 1982, The Stochastic Behavior of Common Stock Variances: Value, Leverage and Interest Rate Effects, Journal of Financial Economics 10, 407-432.

Diebold, Francis, and Glenn Rudebusch, 1990a, A Nonparametric Investigation of Duration Dependence in the American Business Cycle, Journal of Political Economy 98, 596-616.

— 1990b, Measuring Business Cycles: A Modern Perspective, Review of Economics and Statistics 78, 67-77.

Douglas, George, 1969, Risk in the Equity Markets: An Empirical Appraisal of Market Efficiency, Yale Economic Essays 9, 3-45. 
Engle, Robert, David Lilien, and Russel Robins, 1987, Estimation of Time Varying Risk Premia in the Term Structure: the ARCH-M Model, Econometrica 55, 391-407.

Fama, Eugene F., and Kenneth R. French, 1989, Business Conditions and Expected Returns on Stocks and Bonds, Journal of Financial Economics 25, 23-49.

Fratantoni, Michael, and Scott Schuh, 2003, Monetary Policy, Housing, and Heterogeneous Regional Markets., Journal of Money, Credit, and Banking 35, 557-589.

French, Kenneth R., William Schwert, and Robert F. Stambaugh, 1987, Expected Stock Returns and Volatility, Journal of Financial Economics 19, 3-29.

Geltner, David, 1993, Temporal Aggregation in Real Estate Return Indices, AREUEA Journal 21, $141-166$.

Geltner, David M., Norman G. Miller, Jim Clayton, and Piet Eichholtz, 2000, Commercial Real Estate Analysis and Investments (Second edition, South-Western Educational Publishing: Cincinatti Ohio).

Ghysels, Eric, Andrew Harvey, and Eric Renault, 1996, Stochastic Volatility, in Handbook of Statistics , vol. 14 pp. 177-181 North-Holland, Amsterdam.

Ghysels, Eric, Pedro Santa-Clara, and Rossen Valkanov, 2004, Predicting Volatility: Getting the Most out of Return Data Sampled at Different Frequencies, Journal of Econometrics , forthcoming.

Glosten, L., R. Jagannathan, and D. Runkle, 1993, On the Relation between the Expected Value and the Volatility of the Nominal Excess Return on Stocks., Journal of Finance 48, 1779-1801.

Goyal, Amit, and Pedro Santa-Clara, 2003, Idiosynchratic Risk Matters!, Journal of Finance 58, 975-1007.

Hamilton, James, 1989, A New Approach to the Economics Analysis of Nonstationary Time Series and the Business Cycle, Econometrica 57, 357-384. 
Keim, Donald B., and Robert F. Stambaugh, 1986, Predicting Returns in the Stock and Bond Markets, Journal of Financial Economics 17, 357-390.

Lamont, Owen, and Jeremy Stein, 1999, Leverage and House Price Dynamics in U.S. Cities, Rand Journal of Economics 30, 498-514.

Lintner, John, 1965, Security Prices and Risk: The Theory and Comparative Analysis of A.T.\&T. and Leading Industrials, in presented at the conference on The Economics of Regulated Public Utilities at the University of Chicago Business School.

Mahoney, Joseph, Shelley McCarron, Mike Miles, and C.F. Sirmans, 1996, Locational Differences in Private and Public Real Estate Investment, Real Estate Finance 13, 52-64.

Malpezzi, Stephen, and James Shilling, 2000, Institutional Investors Tilt Their Real Estate Holdings Toward Quality, Too, Journal of Real Estate Finance and Economics 21, 113-140.

Merton, Robert C., 1973, An Intertemporal Capital Asset Pricing Model, Econometrica 41, 867887.

— , 1980, On Estimating the Expected Return on the Market: an Exploratory Investigation, Journal of Financial Economics 8, 323-361.

Neftci, Salih, 1984, Are Economic Time Series Asymmetric over the Business Cycle?, Journal of Political Economy 92, 307-328.

Owyang, Michael T., Jeremy Piger, and Howard J. Wall, 2003, Business Cycle Phases in U.S. States., Federal Reserve Bank of St. Louis Working Paper.

Owyang, Michael T., and Howard J. Wall, 2004, Structural Breaks and Regional Disparities in the Transmission of Monetary Policy., Federal Reserve Bank of St.Louis Working Paper.

Plazzi, Alberto, Walter Torous, and Rossen Valkanov, 2004, Expected Returns and the Expected Growth in Rents of Commercial Real Estate, Working paper. 
Schwert, William G., 1989, Why does Stock Market Volatility Change over Time?, Journal of Finance 44, 1115-1153.

— 1990, Stock Volatility and the Crash of 87, Review of Financial Studies 3, 77-102.

Scruggs, John T., 1998, Resolving the Puzzling Intertemporal Relation between the Market Risk Premium and Conditional Market Variance: a Two-Factor Approach, Journal of Finance 52, $575-603$.

Sichel, Daniel, 1993, Business Cycle Asymmetry: a Deeper Look, Economic Inquiry 31, 224-236.

Stambaugh, Robert F., 1999, Predictive Regressions, Journal of Financial Economics 54, 375-421.

Stock, James, and Mark Watson, 1999, Inflation Forecasting, Journal of Monetary Economics 44, 293-335.

Torous, Walter, Rossen Valkanov, and Shu Yan, 2005, On Predicting Stock Returns with Nearly Integrated Explanantory Variables, Journal of Business 77, 380-403.

Turner, Christopher M., Richard Startz, and Charles R. Nelson, 1989, A Markov Model of Heteroskedasticity, Risk, and Learning in the Stock Market, Journal of Financial Economics $25,3-22$.

Whitelaw, R., 1994, Time Variations and Covariations in the Expectation and Volatility of Stock Market Returns, Journal of Finance 49, 515-541. 


\section{Table 1: Descriptive Statistics of Excess Returns Dispersion, Rental Growth Dispersion and Conditioning Variables}

The table reports descriptive statistics of cross-sectional dispersion of excess returns (as defined in equation (1)), of rental growth (as defined in equation (2)) and economic variables. The economic variables are defined as follows: $T S P R$ is the difference between the yield on 10-year and 1-year Treasuries, CSPR is the difference between the yield on BAA and AAA rated corporate bonds, $I N F$ is inflation computed as the growth of the CPI index and $T B 3 M$ is the three-months Treasury bill rate. All variables are measured on an annual basis. Panel A reports the mean, the standard deviation (denoted by $S t d$ ), the $\mathrm{AR}(1)$ coefficient, the sum of the first 3 autocorrelation coefficients $(A R(1-3))$, the coefficients of skewness (Skew) and kurtosis (Kurt), the minimum (Min) and maximum (Max) value in the sample, the value of the Jarque-Bera test $(J B)$ of normality. Panel B shows the correlation matrix. The sample is 34 biannual observations from 1986:6 to 2002:12.

\begin{tabular}{|c|c|c|c|c|c|c|c|c|c|}
\hline \multicolumn{10}{|c|}{ Panel A: Descriptive statistics } \\
\hline Variable & Mean & $S t d$ & $A R(1)$ & $A R(1-3)$ & Skew & Kurt & Min & $\operatorname{Max}$ & $J B$ \\
\hline \multicolumn{10}{|c|}{ Dispersion of Excess Returns } \\
\hline$S_{r, t}^{a p t}$ & 0.070 & 0.025 & 0.748 & 1.799 & 1.080 & 3.365 & 0.036 & 0.132 & 4.116 \\
\hline$S_{r, t}^{\text {ind }}$ & 0.057 & 0.020 & 0.635 & 1.341 & 0.729 & 2.925 & 0.030 & 0.109 & 1.532 \\
\hline$S_{r, t}^{r t l}$ & 0.040 & 0.012 & 0.709 & 1.431 & 0.307 & 2.196 & 0.023 & 0.070 & 1.292 \\
\hline$S_{r, t}^{o f f}$ & 0.062 & 0.025 & 0.259 & 0.434 & 1.289 & 5.082 & 0.028 & 0.146 & 1.630 \\
\hline \multicolumn{10}{|c|}{ Dispersion of Rental Growth } \\
\hline$S_{g h, t}^{a p t}$ & 0.049 & 0.014 & 0.466 & 0.951 & 0.651 & 2.791 & 0.026 & 0.083 & 1.430 \\
\hline$S_{g h, t}^{i n d}$ & 0.042 & 0.014 & 0.676 & 1.549 & 0.307 & 2.464 & 0.016 & 0.071 & 0.658 \\
\hline$S_{g h, t}^{r t l}$ & 0.035 & 0.012 & 0.707 & 1.210 & 0.115 & 2.533 & 0.013 & 0.058 & 0.309 \\
\hline$S_{g h, t}^{o f f}$ & 0.051 & 0.017 & 0.425 & 0.395 & 0.757 & 3.227 & 0.023 & 0.098 & 0.895 \\
\hline \multicolumn{10}{|c|}{ Conditioning variables } \\
\hline TSPR & 0.018 & 0.011 & 0.780 & 1.211 & 0.075 & 1.914 & -0.003 & 0.036 & 1.703 \\
\hline CSPR & 0.009 & 0.002 & 0.851 & 1.958 & 0.570 & 2.113 & 0.006 & 0.014 & 2.954 \\
\hline TB3M & 0.050 & 0.017 & 0.952 & 2.089 & -0.164 & 2.853 & 0.014 & 0.084 & 0.183 \\
\hline INF & 0.030 & 0.014 & 0.322 & 0.871 & -0.042 & 3.511 & -0.004 & 0.064 & 0.380 \\
\hline
\end{tabular}




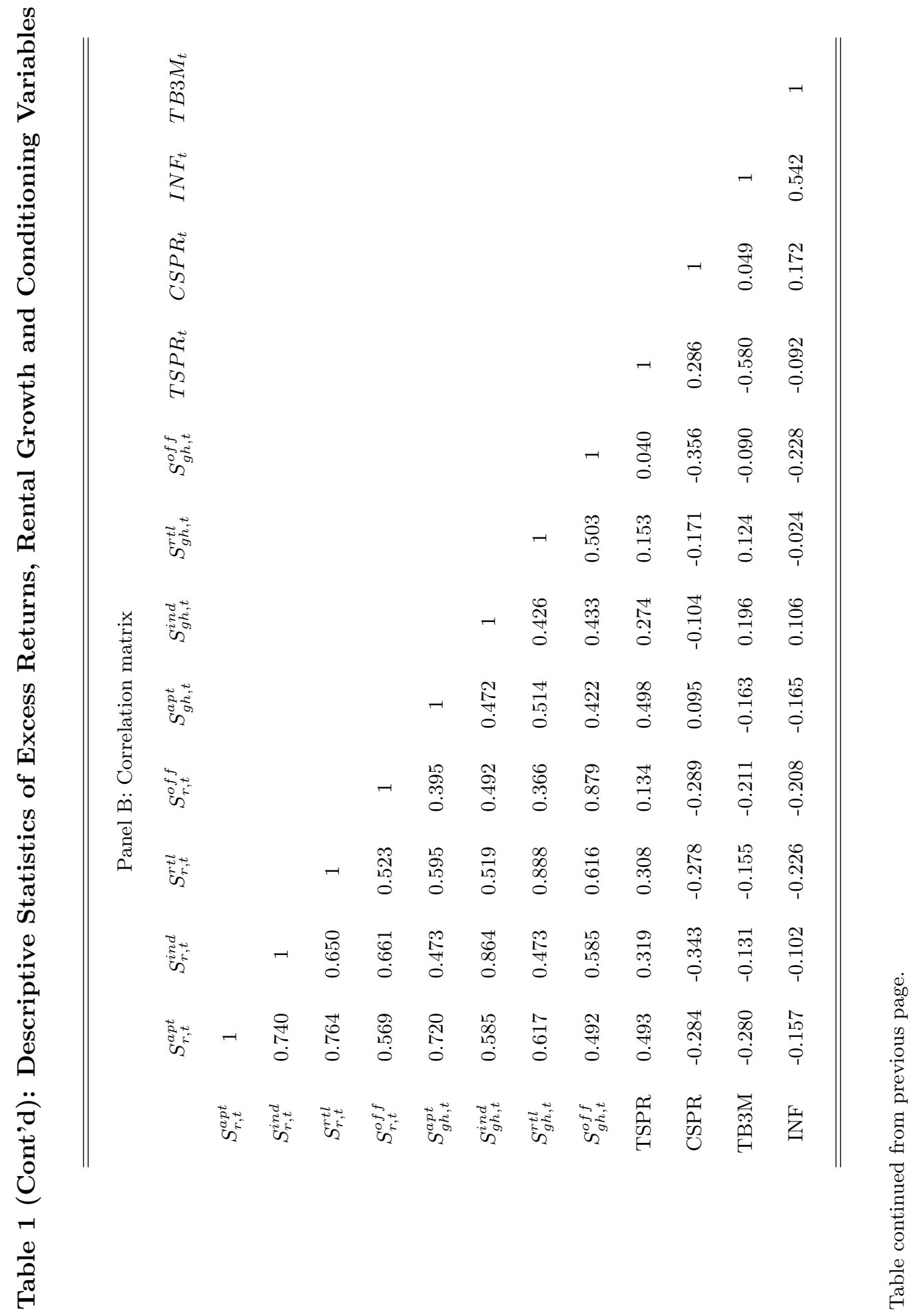




\section{Table 2: Forecasting Regressions of Dispersion of Excess Returns and Rental Growth for the period 1986-2002}

The table reports the results from the SUR regressions by property type of the dispersion of excess returns (Panel A) and rental growth (Panel B) at $t+1$ on economic variables and dispersion at time $t$ for apartments, industrial, retail, and office properties as they appear in equations (3) and (4) respectively. The table shows two specifications for each real estate property type: (1) includes only the economic variables, (2) includes also the lagged dispersion. The economic variables are defined as in Table 1 and $L A G$ is the time- $t$ dispersion. The $p$-values, in parentheses, are obtained using the bootstrapped procedure explained in Section 4.1. The coefficients are bias-adjusted using the same procedure. Significance at the $90 \%, 95 \%$ and $99 \%$ level is denoted with one, two and three asterisks, respectively. The $R_{a d j}^{2}$ goodness of fit measure and the $p$-value of an $F$ test of joint null values are also displayed. The sample is 34 biannual observations from 1986:6 to 2002:12. The forecasting horizon is 1 semester.

\begin{tabular}{|c|c|c|c|c|c|c|c|c|}
\hline \multicolumn{9}{|c|}{ Panel A: Dispersion of Excess Returns } \\
\hline & \multicolumn{2}{|c|}{ Apartments } & \multicolumn{2}{|c|}{ Industrial } & \multicolumn{2}{|c|}{ Retail } & \multicolumn{2}{|c|}{ Offices } \\
\hline & $(1)$ & $(2)$ & (1) & $(2)$ & (1) & $(2)$ & $(1)$ & $(2)$ \\
\hline \multirow[t]{2}{*}{ Constant } & 0.056 & 0.028 & 0.051 & 0.029 & 0.040 & 0.020 & 0.073 & 0.065 \\
\hline & $(0.00)^{* * *}$ & $(0.12)$ & $(0.00)^{* * *}$ & $(0.06)^{*}$ & $(0.00)^{* * *}$ & $(0.04)^{* *}$ & $(0.00)^{* * *}$ & $(0.01)^{* * *}$ \\
\hline \multirow[t]{2}{*}{ TSPR } & 2.077 & 1.352 & 1.380 & 0.907 & 0.601 & 0.261 & 1.067 & 1.042 \\
\hline & $(0.00)^{* * *}$ & $(0.00)^{* * *}$ & $(0.00)^{* * *}$ & $(0.01)^{* *}$ & $(0.02)^{* *}$ & $(0.22)$ & $(0.04)^{* *}$ & $(0.05)^{*}$ \\
\hline \multirow[t]{2}{*}{ CSPR } & -5.035 & -3.398 & -4.181 & -2.834 & -1.597 & -0.792 & -3.899 & -3.926 \\
\hline & $(0.00)^{* * *}$ & $(0.02)^{* *}$ & $(0.00)^{* * *}$ & $(0.03)^{* *}$ & $(0.08)^{*}$ & $(0.31)$ & $(0.04)^{* *}$ & $(0.04)^{* *}$ \\
\hline \multirow[t]{2}{*}{ TB3M } & 0.590 & 0.452 & 0.348 & 0.185 & 0.163 & 0.033 & 0.429 & 0.423 \\
\hline & $(0.07)^{*}$ & $(0.14)$ & $(0.22)$ & $(0.50)$ & $(0.40)$ & $(0.83)$ & $(0.27)$ & $(0.30)$ \\
\hline \multirow[t]{2}{*}{ CPI } & -0.273 & -0.127 & 0.052 & 0.177 & -0.139 & 0.020 & -0.564 & -0.489 \\
\hline & $(0.33)$ & $(0.62)$ & $(0.82)$ & $(0.45)$ & $(0.41)$ & $(0.89)$ & $(0.09)^{*}$ & $(0.15)$ \\
\hline \multirow[t]{2}{*}{ LAG } & - & 0.498 & - & 0.469 & - & 0.573 & - & 0.195 \\
\hline & & $(0.00)^{* * *}$ & & $(0.00)^{* * *}$ & & $(0.00)^{* * *}$ & & $(0.12)$ \\
\hline$R_{a d j}^{2}$ & 0.407 & 0.534 & 0.298 & 0.409 & 0.093 & 0.382 & 0.137 & 0.117 \\
\hline$F-t e s t$ & 0.001 & 0.000 & 0.007 & 0.000 & 0.152 & 0.001 & 0.085 & 0.073 \\
\hline
\end{tabular}


Table 2 (Cont'd): Forecasting Regressions of Dispersion of Excess Returns and Rental Growth for the period 1986-2002

\begin{tabular}{|c|c|c|c|c|c|c|c|c|}
\hline \multicolumn{9}{|c|}{ Panel B: Dispersion of Rental Growth } \\
\hline & \multicolumn{2}{|c|}{ Apartments } & \multicolumn{2}{|c|}{ Industrial } & \multicolumn{2}{|c|}{ Retail } & \multicolumn{2}{|c|}{ Offices } \\
\hline & $(1)$ & $(2)$ & $(1)$ & $(2)$ & $(1)$ & $(2)$ & (1) & $(2)$ \\
\hline \multirow{2}{*}{ Constant } & 0.028 & 0.025 & 0.007 & 0.004 & 0.019 & 0.009 & 0.058 & 0.049 \\
\hline & $(0.02)^{* *}$ & $(0.05)^{*}$ & $(0.53)$ & $(0.69)$ & $(0.08)^{*}$ & $(0.34)$ & $(0.00)^{* * *}$ & $(0.00)^{* * *}$ \\
\hline \multirow[t]{2}{*}{ TSPR } & 0.872 & 0.739 & 1.177 & 0.815 & 0.596 & 0.311 & 0.732 & 0.693 \\
\hline & $(0.00)^{* * *}$ & $(0.01)^{* * *}$ & $(0.00)^{* * *}$ & $(0.00)^{* * *}$ & $(0.02)^{* *}$ & $(0.14)$ & $(0.03)^{* *}$ & $(0.05)^{* *}$ \\
\hline \multirow[t]{2}{*}{ CSPR } & -0.379 & -0.596 & -1.921 & -1.426 & -1.104 & -0.574 & -3.124 & -3.022 \\
\hline & $(0.69)$ & $(0.57)$ & $(0.03)^{* *}$ & $(0.09)^{*}$ & $(0.23)$ & $(0.45)$ & $(0.01)^{* * *}$ & $(0.02)^{* *}$ \\
\hline \multirow[t]{2}{*}{ TB3M } & 0.292 & 0.234 & 0.581 & 0.347 & 0.365 & 0.176 & 0.401 & 0.363 \\
\hline & $(0.16)$ & $(0.29)$ & $(0.00)^{* * *}$ & $(0.06)^{*}$ & $(0.06)^{*}$ & $(0.29)$ & $(0.13)$ & $(0.18)$ \\
\hline \multirow[t]{2}{*}{$\mathrm{CPI}$} & -0.204 & -0.119 & 0.049 & 0.147 & -0.134 & -0.014 & -0.440 & -0.352 \\
\hline & $(0.25)$ & $(0.54)$ & $(0.77)$ & $(0.35)$ & $(0.42)$ & $(0.92)$ & $(0.05)^{* *}$ & $(0.13)$ \\
\hline \multirow[t]{2}{*}{ LAG } & - & 0.229 & - & 0.397 & - & 0.550 & & 0.236 \\
\hline & & $(0.07)^{*}$ & & $(0.00)^{* * *}$ & & $(0.00)^{* * *}$ & & $(0.05)^{* *}$ \\
\hline$R_{a d j}^{2}$ & 0.174 & 0.180 & 0.357 & 0.479 & 0.024 & 0.382 & 0.170 & 0.192 \\
\hline$F-t e s t$ & 0.051 & 0.030 & 0.002 & 0.000 & 0.332 & 0.001 & 0.054 & 0.025 \\
\hline
\end{tabular}

Table continued from previous page. 


\section{Table 3: Economic Significance of the Conditioning Variables}

The table reports the marginal economic significance of the economic variables on the dispersion of excess returns and rental growth rates. The Table reports two entries: the first one corresponds to 2 times the standard error of the regressor times its coefficient, the second is the absolute value of the previous value divided by the average dispersion, as it appears in Table 1. The Tables shows the results corresponding to the two specifications as in Table 2.

\begin{tabular}{|c|c|c|c|c|c|c|c|c|}
\hline \multicolumn{9}{|c|}{ Dispersion of Excess Returns } \\
\hline & \multicolumn{2}{|c|}{ Apartments } & \multicolumn{2}{|c|}{ Industrial } & \multicolumn{2}{|c|}{ Retail } & \multicolumn{2}{|c|}{ Offices } \\
\hline & (1) & $(2)$ & (1) & $(2)$ & (1) & $(2)$ & $(1)$ & $(2)$ \\
\hline \multirow[t]{2}{*}{ TSPR } & 0.044 & 0.029 & 0.029 & 0.019 & 0.013 & 0.006 & 0.023 & 0.022 \\
\hline & $(0.63)$ & $(0.41)$ & $(0.51)$ & $(0.34)$ & $(0.31)$ & $(0.14)$ & $(0.36)$ & $(0.35)$ \\
\hline \multirow[t]{2}{*}{ CSPR } & -0.025 & -0.017 & -0.021 & -0.014 & -0.008 & -0.004 & -0.019 & -0.019 \\
\hline & $(0.35)$ & $(0.24)$ & $(0.36)$ & $(0.24)$ & $(0.19)$ & $(0.10)$ & $(0.31)$ & $(0.31)$ \\
\hline \multirow[t]{2}{*}{ TB3M } & 0.020 & 0.015 & 0.012 & 0.006 & 0.005 & 0.001 & 0.014 & 0.014 \\
\hline & $(0.28)$ & $(0.22)$ & $(0.20)$ & $(0.11)$ & $(0.13)$ & $(0.03)$ & $(0.23)$ & $(0.23)$ \\
\hline \multirow[t]{2}{*}{ INF } & -0.008 & -0.004 & 0.001 & 0.005 & -0.004 & 0.001 & -0.016 & -0.014 \\
\hline & $(0.11)$ & $(0.05)$ & $(0.03)$ & $(0.09)$ & $(0.10)$ & $(0.01)$ & $(0.26)$ & $(0.22)$ \\
\hline \multicolumn{9}{|c|}{ Dispersion of Rental Growth Rates } \\
\hline & \multicolumn{2}{|c|}{ Apartments } & \multicolumn{2}{|c|}{ Industrial } & \multicolumn{2}{|c|}{ Retail } & \multicolumn{2}{|c|}{ Offices } \\
\hline & (1) & $(2)$ & (1) & $(2)$ & (1) & $(2)$ & (1) & (2) \\
\hline \multirow{2}{*}{ TSPR } & 0.018 & 0.016 & 0.025 & 0.017 & 0.013 & 0.007 & 0.016 & 0.015 \\
\hline & $(0.38)$ & $(0.32)$ & $(0.59)$ & $(0.41)$ & $(0.37)$ & $(0.19)$ & $(0.31)$ & $(0.29)$ \\
\hline \multirow[t]{2}{*}{ CSPR } & -0.002 & -0.003 & -0.009 & -0.007 & -0.005 & -0.003 & -0.015 & -0.086 \\
\hline & $(0.04)$ & $(0.06)$ & $(0.22)$ & $(0.17)$ & $(0.16)$ & $(0.08)$ & $(0.30)$ & $(1.70)$ \\
\hline \multirow[t]{2}{*}{ TB3M } & 0.010 & 0.008 & 0.019 & 0.012 & 0.012 & 0.006 & 0.013 & 0.012 \\
\hline & $(0.20)$ & $(0.16)$ & $(0.46)$ & $(0.28)$ & $(0.35)$ & $(0.17)$ & $(0.26)$ & $(0.240)$ \\
\hline \multirow[t]{2}{*}{ INF } & -0.006 & -0.003 & 0.001 & 0.004 & -0.004 & 0.000 & -0.013 & -0.010 \\
\hline & $(0.12)$ & $(0.07)$ & $(0.03)$ & $(0.10)$ & $(0.11)$ & $(0.01)$ & $(0.25)$ & $(0.20)$ \\
\hline
\end{tabular}




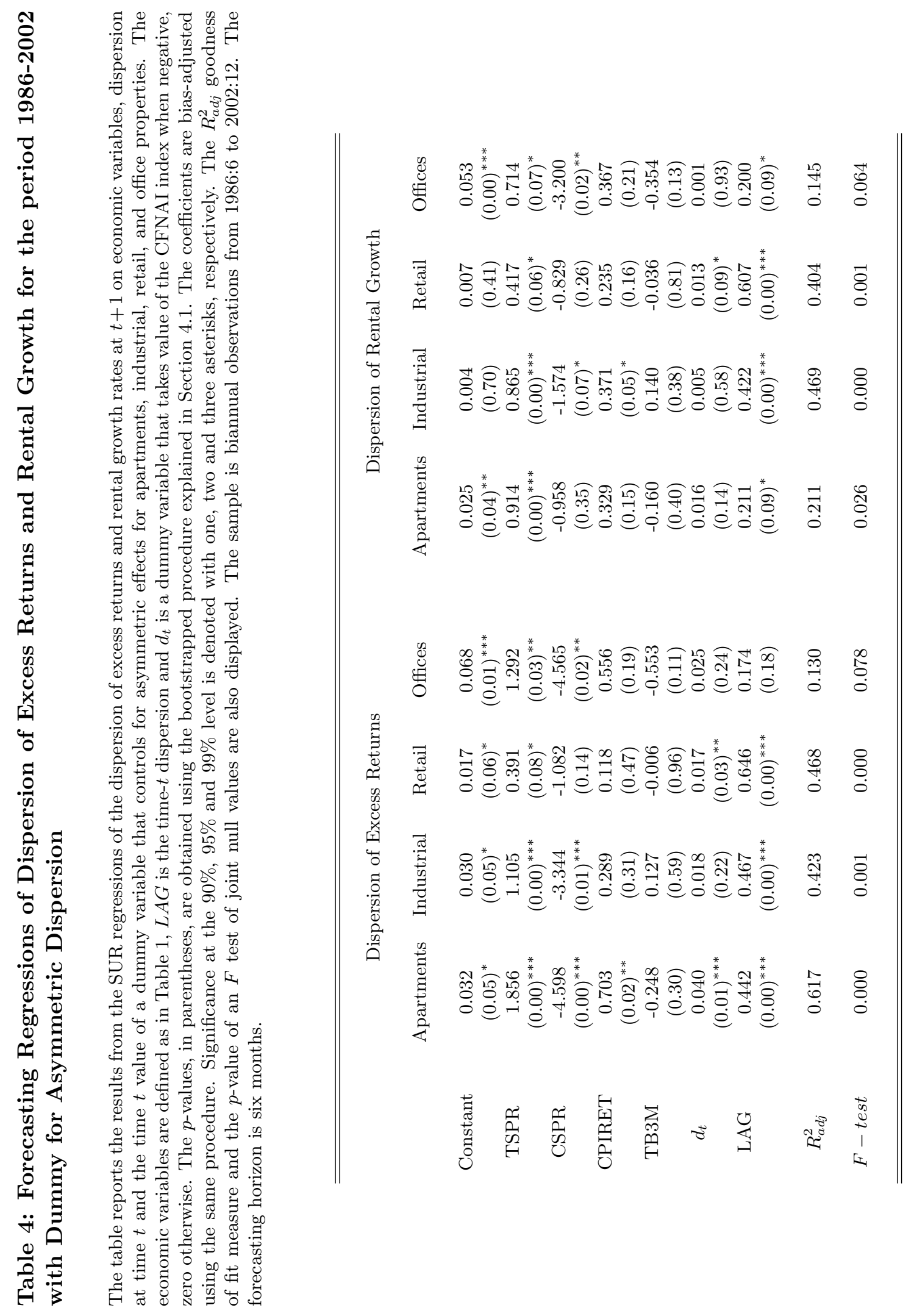




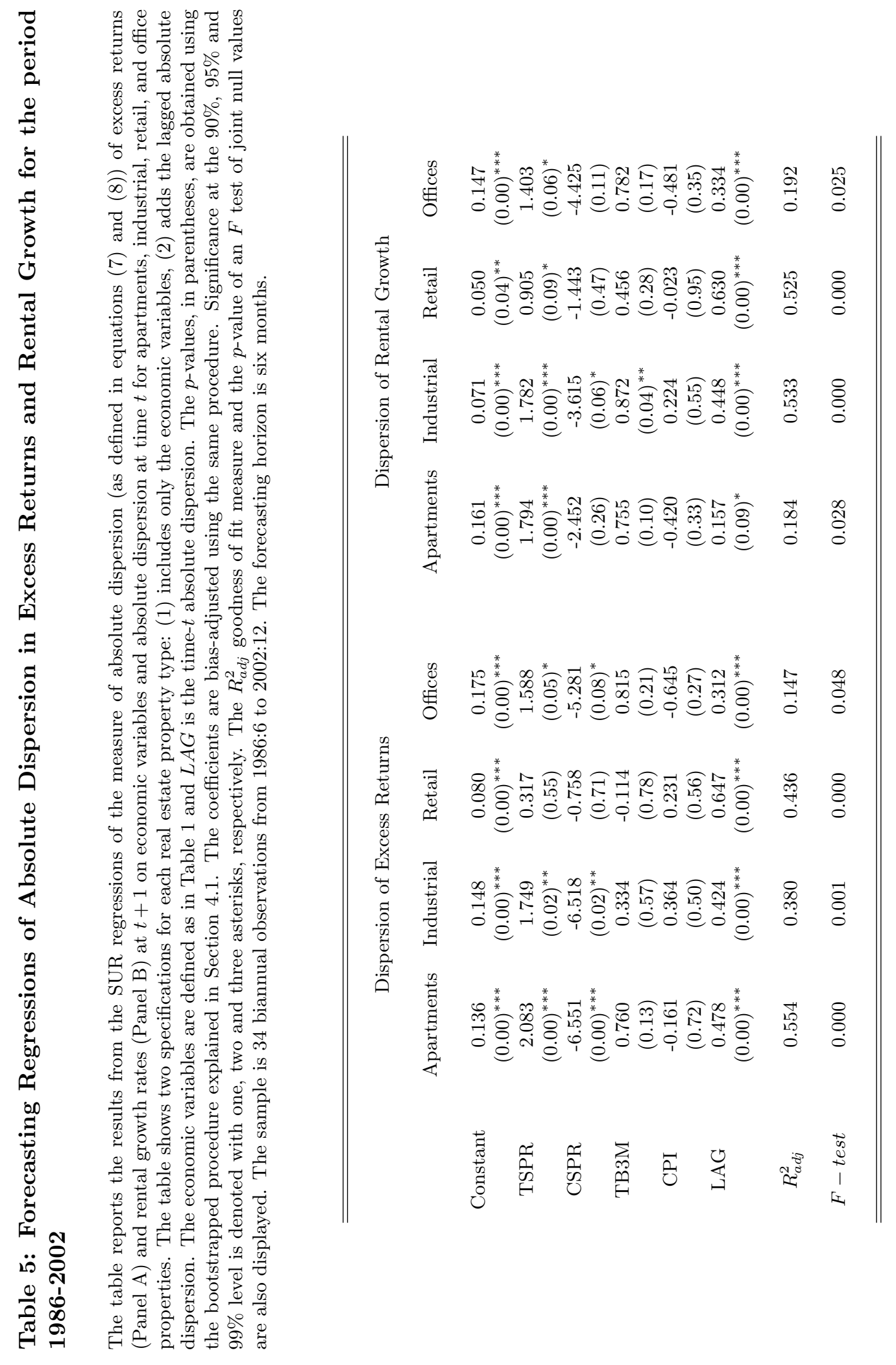




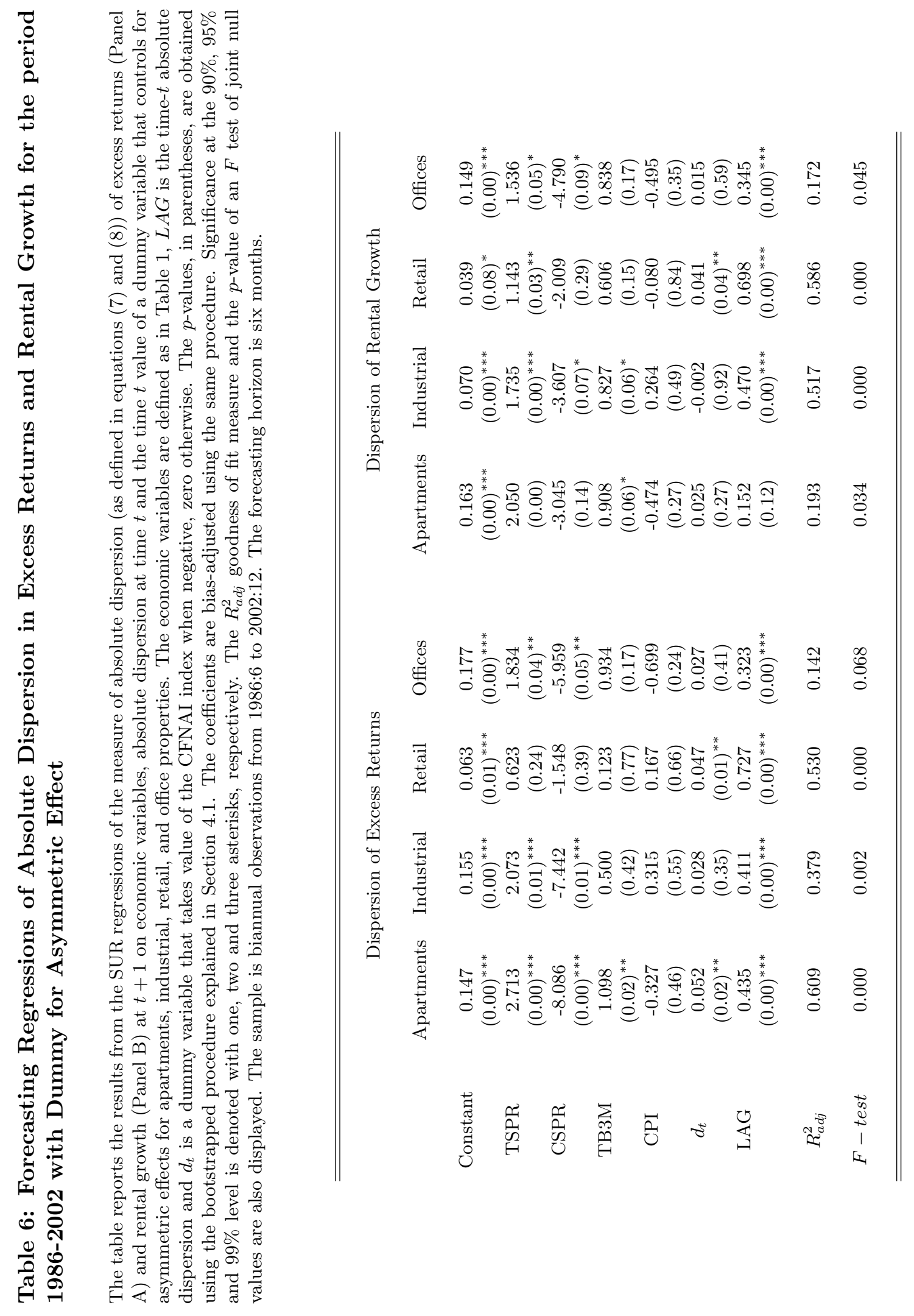




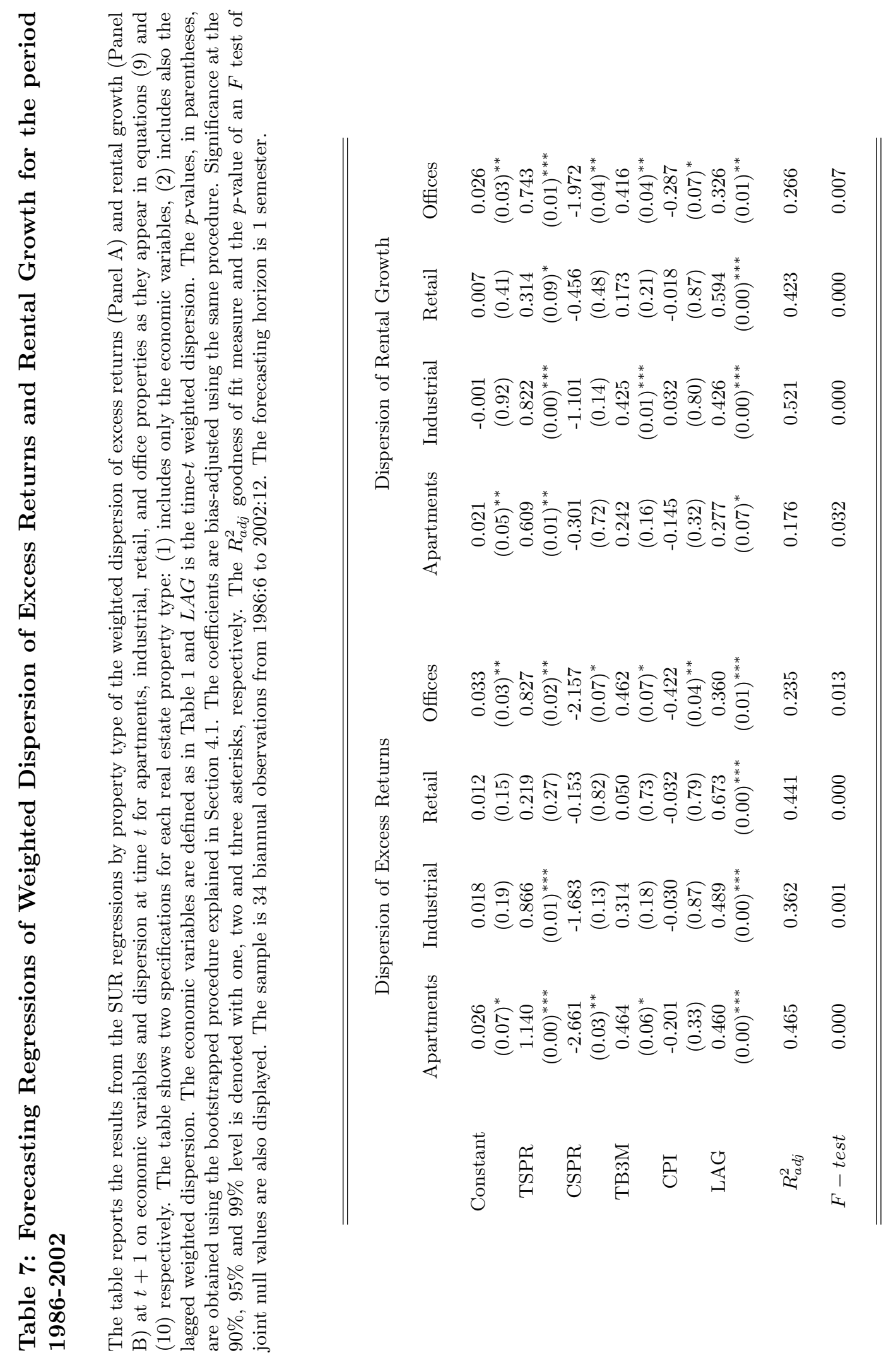




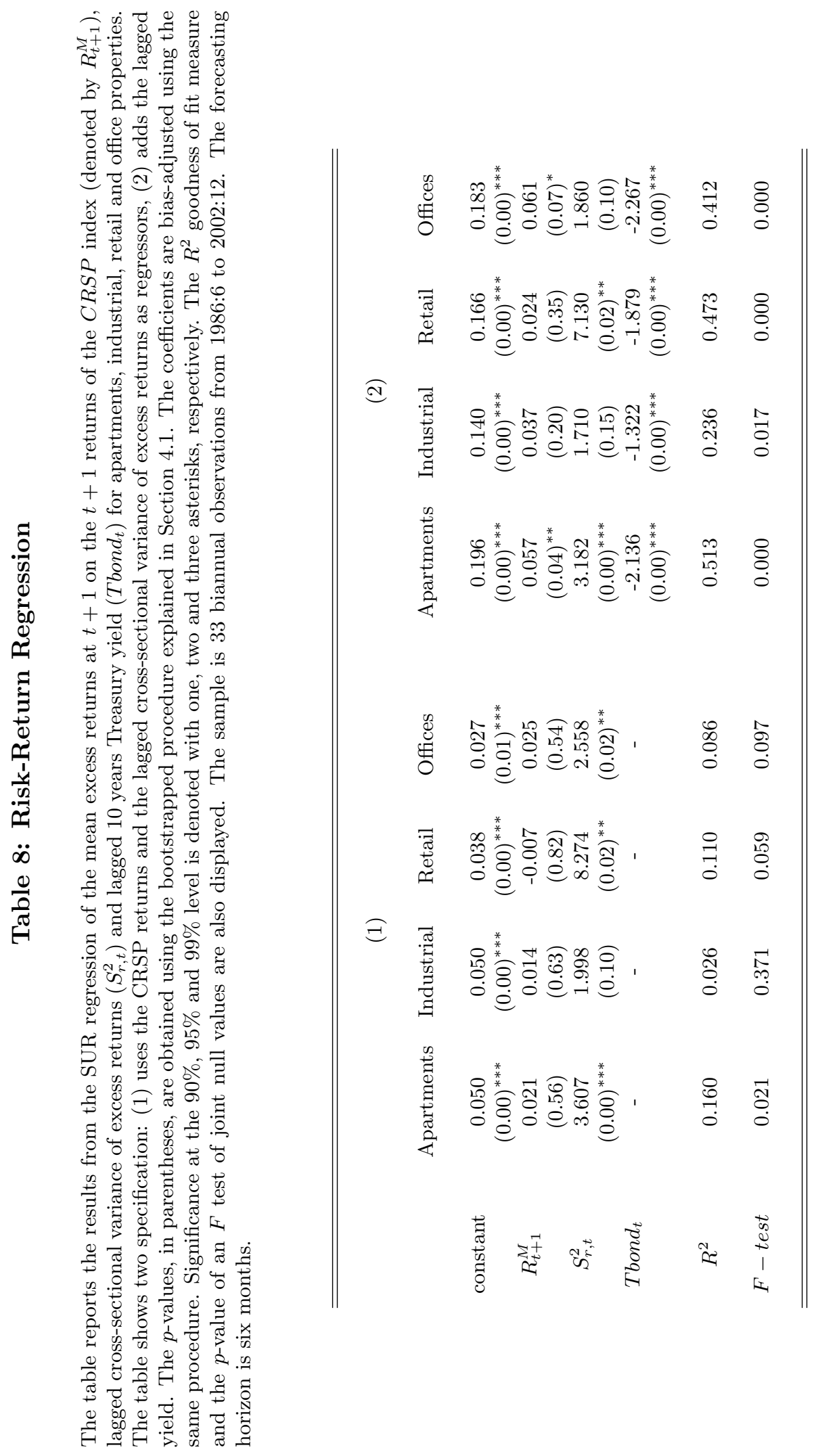




\section{Figure 1: Cross-sectional distribution of excess returns}

This figure shows the cross-sectional mean (solid line), median (asterisk) and interquartile range (error bar) for the cross-sectional distribution of biannual excess returns for all four property types over the 1986:6 to 2002:12 period.
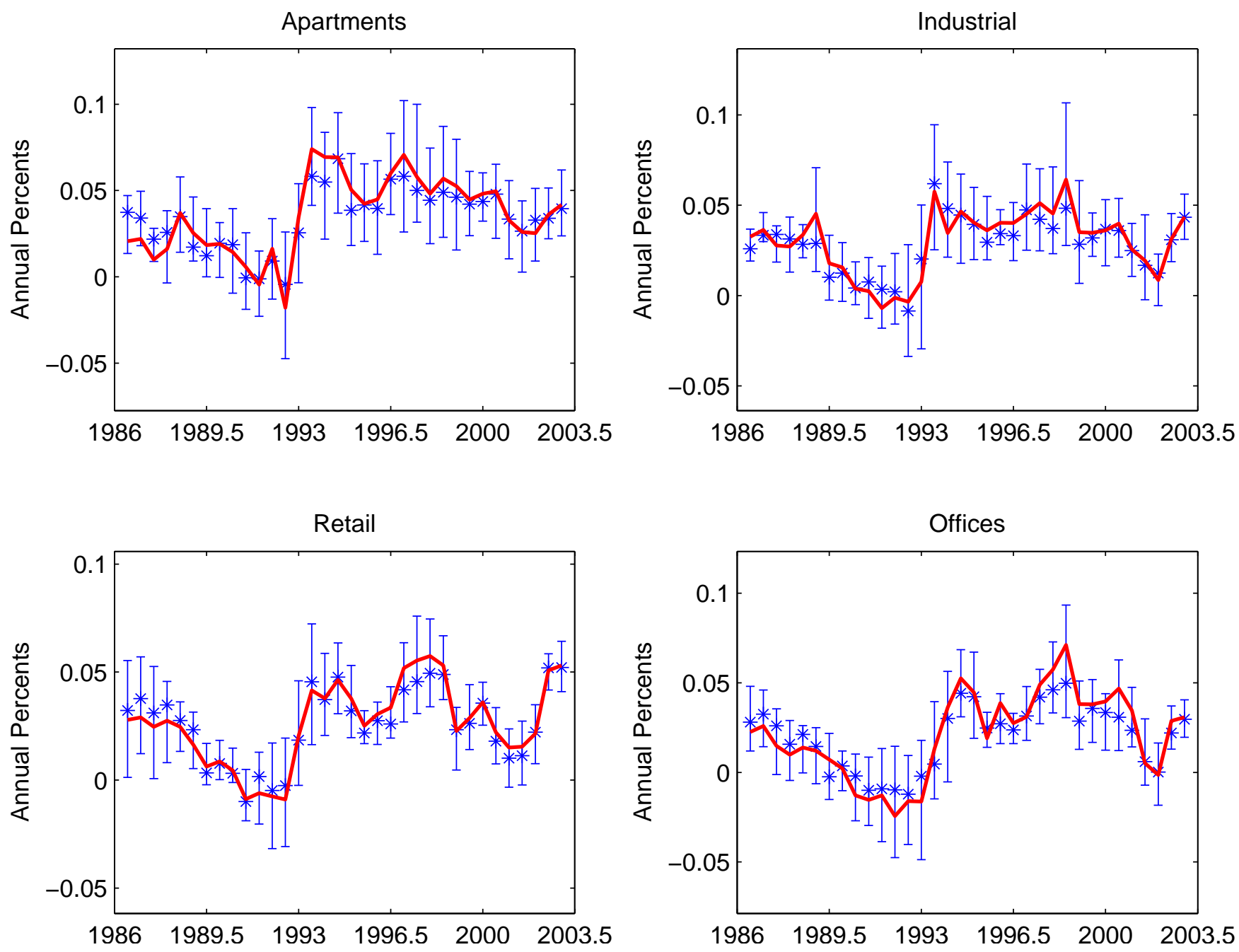
Figure 2: Cross-sectional distribution of rental growth

This picture shows the cross-sectional mean (solid line), median (asterisk) and interquartile range (error bar) for the cross-sectional distribution of biannual rental growth for all four property types over the 1986:6 to 2002:12 period.
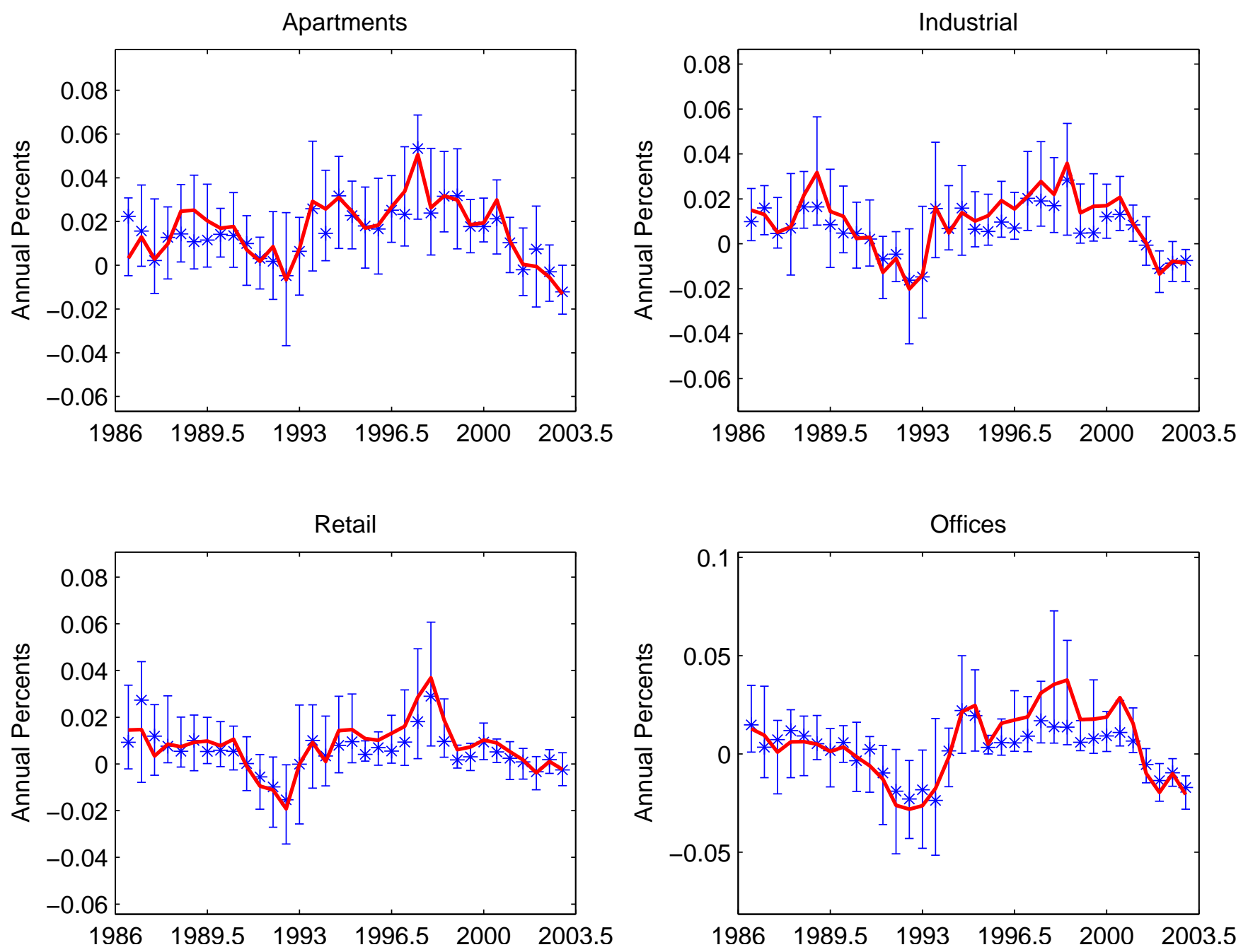
Figure 3: Time Series of $S_{r, t}$ and $S_{g h, t}$

The figure reports the time series plot of the dispersion of excess returns (solid line) and of rental growth (dashed line), as defined in equations (1) and (2), for all four property types during over the 1986:6 - 2002:12 period.
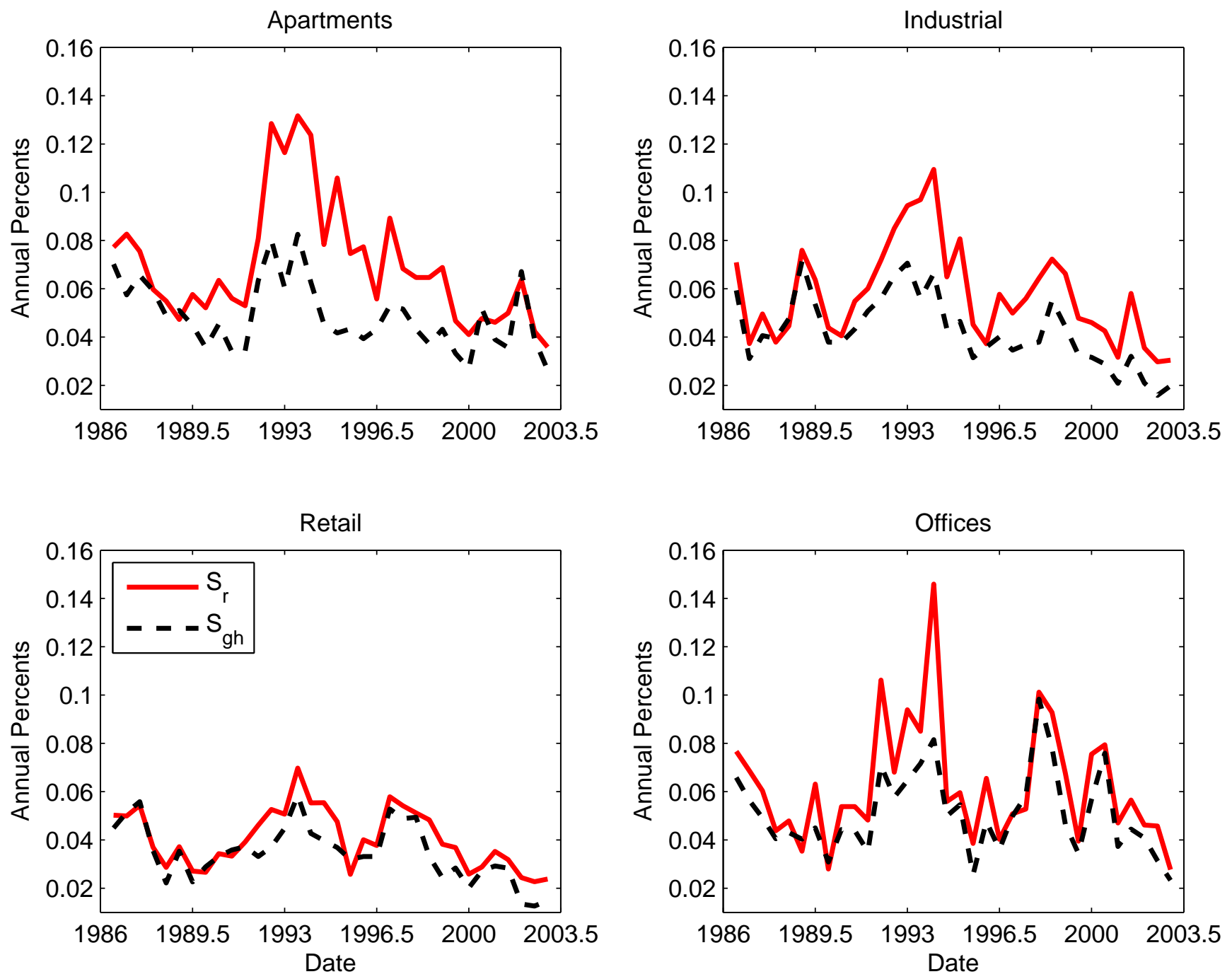